\title{
Mortality-Indexed Annuities \\ Managing Longevity Risk via Product Design
}

Andreas Richter

Frederik Weber

Discussion Paper 2009-14

September 2009

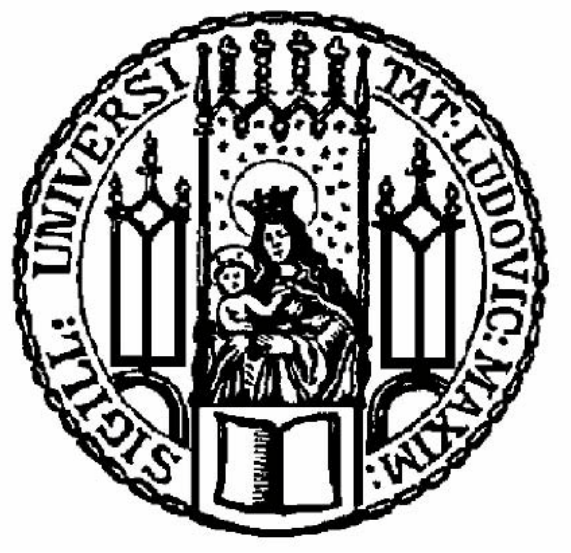

Munich School of Management

University of Munich

Fakultät für Betriebswirtschaft

Ludwig-Maximilians-Universität München

Online at http://epub.ub.uni-muenchen.de/ 


\title{
Mortality-Indexed Annuities \\ Managing Longevity Risk via Product Design
}

\author{
Andreas Richter* $\quad$ Frederik Weber ${ }^{\dagger}$
}

September 2009

\begin{abstract}
Longevity risk has become a major challenge for governments, individuals, and annuity providers in most countries, and especially its aggregate form, i.e. the risk of unsystematic changes to general mortality patterns, bears a large potential for accumulative losses for insurers. As obvious risk management tools such as (re)insurance or hedging are less suited to manage an annuity provider's exposure to aggregate longevity risk, the current paper proposes a new type of life annuities with benefits contingent on actual mortality experience, and it also details actuarial aspects of implementation. Similar adaptations to conventional product design exist in investment-linked annuities, and a role model for long-term contracts contingent on actual cost experience is found in German private health insurance so that the idea is not novel in general, but it is in the context of longevity risk.

By not or re-transferring the systematic longevity risk insurers may avoid accumulative losses so that the primary focus in an extensive Monte-Carlo simulation is on the question of whether and to what extent such products are also advantageous for policyholders in contrast to a comparable conventional annuity product.
\end{abstract}

Keywords: Longevity risk, systematic risk, risk avoidance, mortality-indexed annuities.

JEL Classification: G22; G23; C15.

\footnotetext{
* Institute for Risk and Insurance Management, Ludwig-Maximilians-Universität München, GeschwisterScholl-Platz 1, 80539 Munich, Germany. Phone: +49 89 2180-2171. E-mail: richter@lmu.de.

† Institute for Risk and Insurance Management, Ludwig-Maximilians-Universität München, GeschwisterScholl-Platz 1, 80539 Munich, Germany. Phone: +49 89 2180-3882. E-mail: fweber@bwl.lmu.de. Corresponding author.
} 


\section{Motivation and Introduction}

For quite a while scholars and practitioners - not only with a focus on insurance but also with backgrounds such as sociology, demography, health sciences, and other areas - have been discussing a globally observable phenomenon commonly named demographic transition.11 Strong, sustaining changes of mortality, fertility, migration and other factors have tremendously affected the age structures of most countries' population, and a rapid increase of average individual lifetime is a predominant consequence. Inseparably linked to a reduction of mortality rates at virtually all ages, it may be considered more than welcome from each individual's point of view, and it can also be recognized as a societal achievement and major success of well-functioning public health and old-age care systems, improved working conditions, and also healthier lifestyles.

Often cited as longevity trend, it can be traced back approximately 100-150 years for most Western countries ${ }^{2}$ Looking at female life expectancies in several countries, Oeppen and Vaupel (2002) impressively show that each individual country has experienced a steady growth of lifetime during the past 150 years which is a strong argument supporting this notion. Even more interestingly, when taking together all countries, the existence of a global linear trend also seems to be supported.

The risk of outliving one's savings or other financial resources to cover expenses during retirement could also be understood as some sort of individual longevity risk, but the same term has been used in the literature also to refer to individual fluctuations around a general average mortality, i.e. the risk of living shorter or longer than the average member of the respective group of individuals. In fact, life and pension insurance are based on a balancing of risks across sufficiently large portfolios, and they make explicit use of the individual fluctuations around an average value without which the entire functioning of insurance would have to be put into question. While some annuity contracts terminate sooner some cease later so that the entire portfolio of contracts is eventually balanced, and with an increasing number of policies results stabilize 3

However, the term aggregate longevity risk has been used rather to refer to the additional uncertainty about changes in the underlying patterns, and this particular risk can be considered a major concern for insurers. Because, given a sufficiently prudent selection of the insured portfolio, an insurer can well diversify the unsystematic, individual form of this risk and should on average not suffer losses nor generate gains from mortality differences. The aggregate form can also be considered a systematic risk since it refers to unforeseeable random changes representing strong correlations between single contracts and thus a potential for accumulative losses. Of course, while differences between single countries exist, the aggregate form of this risk becomes even more threatening when seen from an international perspective as would appear suitable for a global primary insurance group or most reinsurers.

Increasing life expectancy has not been paralleled by a similar prolongation of working life, and individuals tend to survive a substantial, increasing number of years beyond retirement age. Thus, individual provision for an adequate and sufficient standard of living has become one of

\footnotetext{
${ }^{1}$ See Montgomery (2007) for a depiction and explanation of different stages of demographic transition.

${ }^{2}$ For a discussion not limited to Western industrialized nations see e.g. United Nations (2005).

${ }^{3}$ See for instance Leinert and Wagner (2001) for an analysis of intergenerational effects in the German private annuities market caused by the longevity trend.
} 
the most pressing challenges for 21 st century societies. Insurance contracts as the traditionally dominating instruments for transferring financial risks offer the possibility to transfer longevity risk exposure by means of life annuity contracts.

Here, the insurer can be considered to be in a situation similar to the short position in a forward contract on the annuitants' survival, and the actual remaining number of years to live is uncertain for both the annuitant and the provider. In the view of the longevity trend it thus seems to be quite risky for an insurer to promise nominally fixed annuity payments contingent on the policyholder's survival - yet this might be the most desirable contract design for the (potential) annuitant. Insurers are thus challenged to reconcile exposure to longevity risk and their customers' growing demand for adequately designed insurance products.

Curiosity has driven research for adequate mortality models for quite some tim 5 yet none of them has been universal enough to accurately fit observed mortality patterns for all countries and all time periods, and it is quite unlikely that such models will ever exist 6

One of the most prominent stochastic models for mortality was proposed by Lee and Carter (1992, henceforth LC), and it has rapidly gained acceptance in academia and among practitioners, which could partly be due to its relative simplicity 7 However, in its original form it has a number of shortcomings, such as the homoscedasticity of error terms, which Alho (2000) criticized as somewhat unrealistic, or a lack of simple implementation. Among a large number of extensions (see, for example, Lee (2000) or Renshaw and Haberman (2003)) is an approach presented by Brouhns et al. (2002) who resort to the notion that the number of deaths can be regarded as a Poisson counting process. This implies that error terms are heteroscedastic, which seems to be more realistic, and their model has also the advantage that parameters can be estimated iteratively, thus greatly facilitating computations. This alternative approach is thus adopted here and will be referred to as PML (Poisson Maximum Likelihood).

It needs to be mentioned that two major concerns persist when applying any model: model uncertainty, i.e. the uncertainty of whether a specific model is at all suitable for describing the underlying data, and parameter uncertainty, i.e. the question of whether - given a specific model - the respective parameters are correctly estimated by using observed data from the past. These potential drawbacks must be accepted as inherent to fitting models to data from the past in order to obtain projections for the future. They cannot be completely avoided, but rather need to be kept in mind when analyzing results. It is a hope that the accuracy and detailedness of models will be further increased, and some restrictions which have existed in the past (such as technical limitations or implementation issues) have become negligible. Ultimately, a wide range of models and sufficient knowledge about when to use which of them can be expected.

Among the typical instruments implemented within a structured, iterative risk management process techniques such as hedging or risk transfer, e.g. through insurance, are widely used.

\footnotetext{
${ }^{4}$ An extensive investigation for how people in Germany have made provisions for their old-age income is provided e.g. by GDV (2004).

${ }^{5}$ Note for instance the well-known early models proposed by De Moivre (1756), Gompertz (1825), or Makeham (1860).

${ }^{6}$ For a detailed overview and a categorization of several stochastic mortality models see e.g. Cairns et al. (2006).

7 For example, the Lee-Carter model served as a starting point for mortality forecasting models used by the U.S. Social Security Administration; see for instance Lee and Tuljapurkar (1998) or Lee et al. (2003) and Edwards et al. (2003).
} 
However, due to the strong correlation and thus potential accumulative losses it may be questioned whether the aggregate form of longevity risk can be insured without restrictions at all. Even when pooled with large reinsurance companies, the systematic risk associated with the longevity trend still prevails and cannot be offset by larger portfolio sizes, i.e. the Law of Large Numbers is likely to fail and not to alleviate the threat affected insurers might be facing.

Successful hedging on the other hand requires that an insurer engages in financial transactions that effectively cancel or offset the exposure to the particular risk in question. Though often proposed, natural hedging, i.e. a balancing of exposures to mortality (life insurance) and longevity risk (annuities), seems at least questionable due to many potential drawbacks. For instance contract terms, relevant ages, or (anti-)selection effects do all speak rather against such an opportunity, but advances in this field could of course provide insurers with an additional tool to mitigate aggregate longevity risk.

Eventually, it may seem worthwhile to resort to another risk management tool: risk avoidance. More precisely, by avoiding to assume the aggregate or systematic portion of longevity risk in annuity contracts, an insurer may effectively reduce this particular exposure. However, since it is usually a key feature of life annuities, the strategy of avoidance effectively means that not the entire risk would be transferred or, equivalently, that to some extent it is ex-post shifted back to the policyholders. Riemer-Hommel and Trauth (2005) claim that such adjustments would be "uncompetitive" but do not further investigate these innovations but instead concentrate on reinsurance and hedging, among other tools.

The present contribution is designed to address the question of how exactly providers could make adaptations to the still predominant "classic" product designs. For this purpose, an annuity type with benefits linked to actual mortality experience is proposed including an underlying actuarial model for calculation and reserving. By not or re-transferring the systematic longevity risk insurers may avoid accumulative losses so that the primary focus in an extensive Monte-Carlo simulation is on the question of whether and to what extent such products are also advantageous for policyholders in contrast to a comparable conventional annuity product.

\section{Risk Avoidance through Product Redesign}

\subsection{Introductory Remarks}

As mentioned before, the choices of hedging or (re)insurance as common risk management tools, which in many other cases are straightforward, seem to be either unavailable or unsuitable for an affected insurance company to adequately manage this type of exposure. If instead annuity providers seek to reduce or diminish their exposure through avoidance of aggregate mortality risk, the most drastic way would of course be to not sell life annuities and similar products at all. Consequently also all the opportunities these products can provide would be forgone, and this "solution" would also deprive individuals or insurees of the opportunity of transferring any part of their personal longevity risk. It thus seems interesting from a welfare point of view whether less drastic risk management options exist that still allow for a transfer of at least the non-systematic portion of the risk. One way of tackling this could be to exclude (or reduce) the provider's exposure to systematic longevity risk. Apart from the immediate fact that insurance companies may have a preference for such a curtailed product, it is less obvious whether or not such adaptation is disadvantageous for policyholders, challenging the asserted "uncompetitiveness" claimed by Riemer-Hommel and Trauth (2005).

A specific redesign of conventional life annuities will be proposed and further analyzed below. 
Note at this point that annuity markets have already seen similar (successful) changes of conventional product designs which will be briefly presented in Section 2.2, and this may serve as a justification for turning away from conventional, established products in the present context, aiming at reducing an insurer's exposure to systematic longevity risk. Also note that potential role models for the exclusion of a specific, "systematic" part of risk otherwise transferred to insurers exist in other lines of insurance, and one such model further discussed in Section 2.3 exhibits similarities to the problem of undesirable aggregate longevity risk exposure in conventional life annuities.

\subsection{Previous Modifications of Conventional Annuities}

"Traditional" life annuities in Germany (and many other countries) have long included a valuable, yet conservative guarantee of a minimum interest rate earned on the premiums paid. As actual returns on the insurers' investments often exceeded these minimum yields the excess amounts were consequently largely distributed to policyholders ${ }^{8}$ This mechanism obviously requires little or no interaction by policyholders, and as long as capital market yields (and thus effective rates of return) were substantially higher than minimum guarantees, insurers could well use the argument of (historically) attractive surplus participation for marketing purposes.

However, more innovative products such as unit-linked or variable annuities have been designed and successfully introduced in the insurance markets. ${ }^{9}$ A distinct feature is the fact that the investment risk is not borne by the insurer but by the policyholder who may often choose from only a limited range of investment bundles offered by the insurer. With an increase of private persons' general interest in capital market investments and awareness of the potential for higher returns against a (higher) risk, investment-linked annuities have gained a sizeable share in the pension products market 10

Despite the admittedly different circumstances of risk "non-transfer", just the transition from no investment performance risk for the policyholder to bearing (some of) it does not only give a counterexample to the notion that policyholders would in general reject any changes to traditional products. Under certain circumstances they might even be interested in taking on a significant share of the risk. Of course, policyholders would only accept this additional risk if they are adequately compensated for, or rather if such an alternative features lower prices or

\footnotetext{
${ }^{8}$ German statutory regulation requires insurers to redistribute at least $90 \%$ of investment returns earned from the policyholders' reserves in excess of the minimum guarantee. Such provisions for Germany, applicable to different "generations" of life insurance and life annuities contratcs are governed by Verordnung über die Mindestbeitragsrückerstattung in der Lebensversicherung (Mindestzuführungsverordnung - MindZV) as of April 04, 2008 (see BGBl. I S.690), Verordnung über die Mindestbeitragsrückerstattung in der Lebensversicherung (ZRQuotenV) as of July 23, 1996 (see BGBl. I S.1190), and Verordnung über die Berechnung und Höhe des Rückgewährrichtsatzes, des Normrisikoüberschusses und des Normzinsertrages in der Lebensversicherung (Rückgewährquote-Berechnungsverordnung - RQV) as of March 28, 1984 (see BGBl. I S.496), respectively. As an industry practice, the actual fraction of redistributed execess returns had often been even higher.

9 The term unit-linked annuities generally refers to deferred annuities where during the accumulation phase the premiums paid are accrued according to the performance of a certain type of investment, chosen or at least influenced by the policyholder, whereas variable annuities also link the actual amount of benefits during the payout phase to an investment performance indicator. In a sense, both products do not promise nominally fixed annuity benefits as would be the case with conventional annuities, but in the former case the amount of benefits can ultimately be determined at the inception date of the payout phase. For a discussion of especially the latter annuity type see e.g. Mutschler and Ruß (2001).

10 Relevant statistical data for e.g. Germany can be found in the series "Statistical Yearbook of German Insurance" which is regularly published by the German Insurance Association (GDV), the most recent being GDV (2008).
} 
additional benefits in comparison to the "conventional" product, and this is likely to depend on their individual degree of risk aversion. ${ }^{11}$

Not to be overlooked is the observation that the notion of benefits being linked to demographic development in general, or mortality experience in particular, may actually be not so uncommon in some countries. For instance, the German public pension system, which is organized on a pay-as-you-go basis, delivers benefits that are set by statutory ordinance including a so-called "demographic factor". Thus no ultimate guarantee as to the exact amount of pension payments can be made during the working life, and also thereafter benefits may be changed by legislators as appropriate. Naturally, the demographic transition has also had an impact on population age structures in Germany, and as a consequence social security benefits have barely compensated for inflation. Despite an entirely different range of problems and challenges associated with public pay-as-you-go pension systems, this thought should contribute to the notion of benefits contingent on mortality experience being considered as an interesting design option.

\subsection{An Example for Policies Shifting Insurance Risk Back to the Insured: German Private Health Insurance}

The above mentioned idea of linking annuity benefits not to investment performance but to actual mortality experience - be it that of a given portfolio of insureds, of an insurance company, the insurance industry as a whole, or a specific country's population - is not a novel idea in the sense that products accounting for loss experience would not exist. However, due to the extreme long-term character of life annuity contracts, which can easily exceed 40 years, it is not a trivial problem to connect the actual realizations of the insured risk to future benefits.

A comparable concept can for instance be found in insurance contracts as they are common in the German private health market 12 With the exception of civil servants, freelancers, and higher-income earners, these products are mostly just supplemental for the vast majority of the population, which are generally covered by the public health insurance branch of the German social security system. However, the basic actuarial concept of long-term health contracts is similar to life annuities, and this is a distinct feature in comparison to many countries where health insurance bears more similarities to property/casualty insurance ${ }^{13}$ In exchange for recurring constant premium payments, health care costs are covered for the entire lifetime of the insured person. This way, excessive costs for increasingly needed medical procedures at older ages are avoided at the cost of premiums that are higher than necessary at younger ages.

Another similarity is the fact that it would be a special challenge to adequately predict the future development of health care costs at the time of contract inception. Generally speaking, the health care cost inflation has historically been higher than e.g. the consumer price index development, and in tendency further innovations in medical procedures and techniques also lead to more expensive treatments. This special type of uncertainty can be compared to the

11 The rare case of risk lovers longing to forgo guarantees without any compensation from the annuity provider seems quite absurd here, as such individuals might be inclined to refrain from buying insurance anyway.

12 See Brünjes (1990) for specific technical details regarding Germany. Timmer (1990) provides a multi-country comparison.

13 This is the case e.g. in the US where health insurance is mostly sold on an annual basis without premium guarantees but typically with an option for the insured to annually renew the policy. For further details see e.g. Black and Skipper (2000, p.140ff). 
aggregate form of longevity risk, where a general tendency can be identified but where the exact future development is hard to determine.

To enable insurers to still provide lifelong coverage despite cost inflation, premiums may be increased (and also have to be lowered) in the case and to the extent that actual benefits paid for a portfolio of policies exceed (or under-run) presumed amounts, i.e. if current premiums turn out to be insufficient (or higher than necessary). Of course, as it does not seem advisable to make such adjustments every time the actual expenses in a period even marginally differ from previous projections, legislation in Germany requires expenses to be above or below a certain threshold in order for premium adjustments to be permissible. Effectively, policyholders thus bear the risk of systematic health care cost increases, which the insurer may completely pass on, and in this context it has also been named premium risk; see e.g. Kifmann (2000, 2002 ). It is also obvious that the extent of premium increases or decreases highly depends on whether a certain trend of health care cost development is already incorporated in the rate making process. Yet, the scope for such assumptions is also limited by the marketability and competitiveness in the market, and health insurers in Germany do generally not make use of projections for their rate making.

The concept of shifting back a systematic risk to policyholders could also be transferred to annuity markets, where annuity providers seek to manage or mitigate their exposure to systematic longevity risk, and this notion will be further discussed in the following.

\subsection{Implementation Issues and Appraisal}

Recurring to the other major alteration of conventional annuity design that has been mentioned earlier, investment-linked products shift some part of the risk back to the policyholders. Despite some similarities there are also some pronounced differences in comparison to annuity benefits that are made dependent of a portfolio's actual mortality experience, and those will be briefly pointed out.

While in the case of mortality-linked annuities or adjustable health insurance products it is the insurance industry that has a strong incentive to dispose itself of the highly correlated risks of health cost inflation or - analogously - aggregate longevity ${ }^{14}$ to avoid potential accumulative losses, this is less likely the case with investment-linked products. Rather a general interest of policyholders in participating in higher capital market returns may be the driving force here.

However, investment performance can hardly be influenced by policyholders, especially when thinking of the general average individual and the extremely long contract terms. Thus, moral hazard does not seem to play a role in this case. On the other hand, in health insurance there is a great potential for such unobservable policyholder behavior, and it must be thoroughly accounted for. The actually observable increase of health care costs may in part be due to expost moral hazard arising from the fact that policyholders once in need for (covered) medical procedures consume (motivated by themselves; see Feldstein (1973, p.252)) or receive (through medical providers; see e.g. Feldstein $(1970,1971)$ ) more or more expensive treatments than they would without insurance coverage, i.e. when paying out of their own pocket, which can be considered a quantity effect 15 Note that in incomplete "repair markets" there is also a price

${ }^{14}$ This notion could also be applied to brevity, i.e. shorter than expected lifetime, due to e.g. pandemics or catastrophe events.

15 Nell et al. (2009) investigate the effect of insurance on "repair markets" and this includes the demand for "medical repairs". Since it is impossible to write complete insurance contracts, often rather actual expenses are compensated for, and this has an effect on repair markets; see e.g. Feldstein (1970), Zweifel and Crivelli 
effect due to a limited price elasticity, and this contributes additionally towards increasing health care costs. Fortunately, these effects would not be present in the case of indexed life annuities. In particular, it is quite unlikely that policyholders have any possibility to intentionally expand their respective individual lifetimes once insurance coverage is provided.

However, another type of asymmetric information is equally inherent to both health insurance and life annuities. In neither case does the insurer know as much about the health status (or the "true" life expectancy) as the individual herself. In health insurance, it is thus common to use extensive questionnaires or even require medical examination reports prior to the contract acceptance. The intention is to overcome this asymmetry and offer accordingly discriminated premiums that account for the individual health status. In the annuities business, however, such premium discrimination is largely inexistent with few exceptions so far ${ }^{16}$ Instead, premiums are calculated based on almost the "worst case", i.e. assuming that insured persons experience rather long lifetimes. Presuming that individuals have a relatively precise understanding of what their individual life expectancy is (which could well be questioned), those with a poorer than average health status are thus likely to be driven out of these markets. Consequently, conventional products in tendency rather attract persons with higher life expectancies, and in tendency the portfolio of insured is composed only of individual risks representing the poorest quality from the provider's perspective ${ }^{17}$ The extent to which such anti-selection occurs in the annuity market might also be dependent on the characteristics of the annuity contracts offered. In particular, the fact whether immediate or deferred annuities at variable or fixed annuitization conditions are offered or whether they include a lump-sum payout option at some age(s) are likely to have an influence on the degree of adverse selection. Further investigation into these issues is beyond the scope of this contribution, though.

While premium adjustments in the German private health insurance business are triggered by the experience of a suitably confined portfolio of contracts, it is up to the insurer to determine this partitioning, and for outside stakeholders in general or policyholders in particular it may be difficult to retrace the insurer's decision. Furthermore, the credibility of actual cost experience is at least limited from the policyholders' point of view unless they are based on industry cost figures. A similar consideration of course applies to the case of actual mortality experience as a basis for indexed annuities. Unlike the question of what health care costs exactly are to be considered, it seems hardly disputable how deaths are to be counted. However, the maximum possible degree of objectivity and traceability can only be reached when the general population mortality as published by a governmental statistics agency or an official actuarial authority is the basis for further considerations. For instance, in the UK the Government Actuary's Department (GAD) is in charge of publishing life tables. Naturally, the general population's or insured persons' mortality is not necessarily identical to a specific annuity provider's experience. The opposite extreme would be to base any sort of adjustments on the experience of an insurance company or even a specific portfolio, thus completely dispelling basis risk at the cost of limited transparency ${ }^{18}$ No general recommendation on this

(1996), or Pavcnik (2002).

16 Impaired or enhanced annuities aim at providing higher benefits for individuals with a significantly poorer health status upon sufficient proof by the policyholder. Schumacher (2008) further analyzes these products, which seem to be established only in the UK annuity market but are not yet common elsewhere.

17 This is just the famous example of Akerlof's "lemons" (Akerlof 1970) where under asymmetric information without remedies only the worst quality in the market is eventually traded.

${ }^{18}$ In investment-linked annuities as briefly mentioned in Section 2.2 the general idea is to connect the policy 
particular issue can be made here, but the trade-off between transparency and basis risk has to be pondered in each case.

The bottom line of the above deliberations is that neither of the two presented cases exactly mirror the challenge of transferring aggregate longevity risk in life annuities to the policyholders through an appropriate redesign of conventional products. However, both do, firstly, give a strong example of successful changes to conventional products and, secondly, may serve as a rough guideline for how actual losses or expenditure experience can be used for adjustments of premiums or (as will be the case here) benefits.

For annuities of the above-mentioned type making benefits contingent on actual mortality experience the term mortality-indexed annuity (MIA) will be used throughout this paper. Surprisingly, such products do not seem to be offered yet by insurers in the most important insurance markets nor visibly discussed in academia 19

Acknowledging that it may not be immediately desirable for policyholders not being able to transfer their entire longevity risk exposure, it has to be kept in mind that the aggregate form of longevity risk bears a great threat for insurers. Thus, the "solution" represented by the proposed MIA could be a step in the right direction for annuity providers to get this highly correlated risk under control. Such a means of risk avoidance (or reduction) might also foster sluggish annuity markets, and eventually it may be better if insurers offer curtailed products rather than none at all.

\subsection{Proposed Product Features}

As was suggested before, it remains to be decided how specifically an annuity provider can reduce or eliminate aggregate longevity risk exposure from the contracts offered in the insurance market. In the "plain vanilla" case of a single premium immediate annuity (SPIA), there is no recurring premium that could be adjusted like in German health insurance. Consequently, the benefits are one remaining parameter, and in fact there is no necessity for benefits to be constant or nominally fixed throughout the contract term nor in any fashion pre-determined ${ }^{20}$

The innovation proposed here is that at specified intervals the insurance company will adjust the benefits of a mortality-indexed annuity for the remaining periods (contingent on survival) in a way that reflects the difference between actual mortality experience and anticipated values since the most recent adjustment date, keeping in mind the above mentioned trade-off between basis risk for the insurer versus transparency in terms of the relevant underlying portfolio ${ }^{21}$ Simply speaking, if more insureds than anticipated are still alive, benefits have to be cut in

reserves to a specific funds' development. If instead an overall stock index performance or other comprehensive indicator is considered - regardless of how exactly these funds are invested - those contracts would rather be called equity-indexed annuities; see for instance Tiong (2000), Lee (2003), or Lin and Tan (2003).

19 A web search on both www.google.com and scholar.google.com in February 2009 did not yield any results for the keywords mortality [-| ] indexed annuit[y|ies], and for the keywords indexed annuit [y|ies] none were related to actual mortality experience.

20 This is to be understood from a pure actuarial perspective at this point. In reality it is likely that legal and statutory requirements limit the possibility for variable annuity benefits. For instance, to qualify for favorable tax deferral, non-investment-linked life annuity contracts in Germany may only offer constant or increasing payments which excludes decrements; cf. BMF-Schreiben, Decmeber 22, 2005 IVC1-S2252-343/05, Rz 20.

${ }^{21}$ For the sake of simplicity, in the following it will be assumed that adjustments in MIA contracts can be based on the respective portfolio's mortality experience without regulatory objection. 
order to still guarantee lifelong payments given the higher number of survivors. Alternatively, a higher number of deaths will lead to increased benefits for the (fewer) survivors.

More frequent than annual revisions may be meticulous, but are likely to be too timeconsuming or complicated, especially in the view of limited or lagged data availability, and thus appear less worthwhile. It is understood that statutory provisions may actually limit the choices for an insurer, but referring again to the role model of German private health insurance, an annual cycle seems both sensible and feasible if the specific portfolio serves as a reference point. As insurers cannot predict future overall mortality tendencies either, it is further assumed that adjustments of benefits should be made on the basis of a best estimate using actuarial practice and expertise. Again, regulators may determine specific methodologies or models to be applied for this purpose, and for the subsequent analysis one such provision based on the Lee-Carter model introduced above will be presented in Section 3.2 .

\section{Investigating Mortality-Indexed Annuities}

\subsection{Model Setup}

The mortality-indexed annuity (MIA) with the basic features outlined in Section 2.5 is to be further analyzed here. Especially the question of whether from a policyholder's perspective such an innovation tends to be advantageous or not is not yet answered, while clearly annuity providers should have a special interest in dispelling the aggregate longevity risk inherent to conventional life annuities. By means of a Monte-Carlo simulation different developments of actual, previously unknown mortality are investigated regarding their effect on the mortalityindex annuity proposed, i.e. a large number of scenarios is generated and results thus obtained are further analyzed.

Assuming in a first step - as mentioned before - that the experience from the respective insurer's portfolio is drawn upon when making adjustments to the remaining survivors' annuity benefits (or face values) $F V_{t}$ at time $t$, a sufficiently large portfolio of identical annuity contracts is considered with an initial size of $l_{x}$ at time $t=0$. Insured persons in the considered pool are assumed to be homogeneous in the sense of identical risk exposures and identical monetary amounts stipulated in their contracts. ${ }^{22}$ This also includes an identical age $x$ at $t=0$ as well as the same gender for all insured so that effectively only a single cohort is considered. The contracts are assumed to be sold to policyholders against a single upfront premium in the amount of $\pi_{0}$, which can also be considered the initial per-contract reserve $V_{0}$, and the premium is considered to be exogenously given throughout the entire analysis.

Given a best estimate of future mortality, the annual benefit $F V_{0}$ is set at time $t=0$ for the remaining annuity term of $T$ years using the equivalence formula 23

\footnotetext{
${ }^{22}$ For the purpose of profit sharing and attributing investment returns to individual contracts, German insurers are required to split their entire portfolio into smaller groups of similar contracts (Abrechnungsverbände) in order to reflect the different characters of e.g. term life insurance versus life annuities. This notion resembles the assumed homogeneity of the portfolio.

23 The symbols in the formal expressions below follow the International Actuarial Notation standard as introduced in many actuarial text books; see e.g. Bowers et al. (1997).
} 


$$
\begin{aligned}
\pi_{0}=V_{0} & =F V_{0} \cdot \ddot{a}_{x: T}^{1} \\
\text { so that } \quad F V_{0} & =\frac{V_{0}}{\ddot{a}_{x: T}^{1}} \\
& =\frac{\pi_{0}}{\ddot{a}_{x: T}^{1}}
\end{aligned}
$$

Here, $\ddot{a}_{x: T \mid}^{1}$ is the actuarial present value of a $T$-year unit life annuity immediate ${ }^{24}$ as determined using the mortality information and projections available at time $t=0$ and assuming a constant discrete interest rate of $i$ per period (or year). Such a "pure" life annuity pays a unit for as long as a person initially aged $x$ is alive, but not beyond his or her $(x+T)$-th birthday, i.e.

$$
\ddot{a}_{x: T \mid}^{1}=\sum_{k=0}^{T-1}\left\{{ }_{k} p_{x} \cdot v^{k}\right\} \quad \text { where } \quad v=\frac{1}{1+i}
$$

For each future point in time $t$ the insurer determines the respective per-contract reserve $V_{t}$ for the remaining survivors. Based on this information future annuity benefits $F V_{t}$ are set considered to be valid from time $t$ on for the remainder of the contract term unless further deviations from expected mortality developments occur.

Given that $l_{x+t-1}$ insured were alive at the beginning of the previous year $t-1$ the number of survivors at time $t$ is $l_{x+t}$. The new per-contract reserve $V_{t}$ for survivors is then determined by considering which amount could be brought forward from the previous period, i.e. the previous year's reserve less the annuity payment at the beginning of the previous period - accrued at interest, but also accounting for the redistribution of the reserves from those who passed away in the meantime to those still alive. This can also be considered an inheritance effect or survivor bonus 25

More formally, at time $t$

$$
\text { we require } \quad \begin{aligned}
l_{x+t-1} \cdot \frac{V_{t-1}-F V_{t-1}}{v} & =l_{x+t} \cdot V_{t} \\
\text { so that } \quad V_{t} & =\frac{l_{x+t-1}}{l_{x+t}} \cdot \frac{V_{t-1}-F V_{t-1}}{v} \\
& =\frac{V_{t-1}-F V_{t-1}}{v \cdot l_{x+t} / l_{x+t-1}} \\
& =\frac{\left(V_{t-1}-F V_{t-1}\right) \cdot(1+i)}{l_{x+t} / l_{x+t-1}}
\end{aligned}
$$

Note that all these computations are based entirely on already observable information, since at time $t$ it should be known to the annuity provider how many insureds have survived and how many were alive at the beginning of the previous period. At this point, projections or forecasts are thus not needed.

${ }^{24}$ An annuity immediate pays benefits in advance at the beginning of each period whereas an annuity due pays in arrears at the end of each period - both contingent on the insured person still being alive at the beginning of the respective year.

25 Ruß (2000) comments on different mechanisms how to combine death and survivor benefits in investmentlinked insurance products recurring to these effects as basic principles of insurance. In fact, the Law of Large Numbers explicitly balances individual differences in mortality to guarantee a stable average value. See also Blake et al. (2003). 
Given that the actual per-contract reserve $V_{t}$ has been determined, the new (adjusted) benefit $F V_{t}$ is set in a similar way as at time $t=0$; see 3.2 :

$$
\begin{aligned}
V_{t} & =F V_{t} \cdot \ddot{a}_{x+t: \overline{T-t}}^{1} \\
\text { so that } \quad F V_{t} & =\frac{V_{t}}{\ddot{a}_{x+t: \overline{T-t}}^{1}}
\end{aligned}
$$

Of course $\ddot{a}_{x+t: \overline{T-t}}^{1}$ is the updated actuarial present value of a $(T-t)$-year annuity immediate for a person now aged $x+t$ made at time $t$, relying on a new best estimate for future mortality at that time.

It is insightful at this point to consider a situation where initial mortality expectations are correct and do not have to be revised, i.e. actual developments of mortality exactly follow the longevity trend incorporated at the contract inception. Of course, this case is just the absence of systematic risk. As mortality is not deterministic either, fluctuations of individuals' mortality around the (correctly forecasted) general average still occur so that in this case unsystematic risk is the only source of uncertainty. However, if we consider a theoretically infinite number of contracts in a portfolio, the Law of Large Numbers guarantees that individual fluctuations balance, and on average the insurer does not experience deviations from the projected trend in the sense that actual relative frequencies of death exactly correspond to the probabilities predicted by the model ${ }^{26}$ In this hypothetical case, the evolution of reserves as per (3.5) exactly follows the initial calculation made in (3.1), and at every point in time the reserves brought forward from the preceding period exactly match the required funds for future payments in the (then constant) amount of $F V_{t} \equiv F V_{0}$. Eventually, in year $T$ (or rather at the beginning of the $T$-th period) no deficits nor excess reserves are due, which effectively means that on an actuarial basis the insurer would not have losses nor profits.

However, as in reality portfolio sizes will always be finite numbers there is some uncertainty with respect to the difference between relative frequencies and projected probabilities, and even in the absence of systematic longevity risk (i.e. if projections are still perfect on average) the insurer experiences deviations of the actual evolution of the portfolio reserves as per (3.5) from previous expectations so that adjustments of benefits might still be necessary. This deliberation shows that in the product proposed so far, both the systematic and the unsystematic longevity risk are shifted back to policyholders, and they are only able to insure the individual longevity risk in the sense that lifelong payments (but not beyond age $x+T-1$ ) are guaranteed. However, benefits are variable and might deviate from the initial level. Further comments on this model feature will be made later.

It should also be emphasized here what has been a consistent assumption throughout the above equations. All calculations and subsequent analyses are made on a net actuarial basis, i.e. only the actuarial risk is taken into account. In particular, no surcharges or loadings to cover acquisition expenses, no surplus accrual and thus distribution mechanisms, and no statutory or regulatory requirements or restrictions in terms of reserving, investments, or product features are included unless specifically mentioned.

Another major concern that is relevant for the present analysis is model uncertainty, and a vital discussion of quite varying models to predict future mortality has been in the focus of

\footnotetext{
${ }^{26}$ Again, note that model uncertainty is ignored here, assuming that the general type of stochasticity underlying mortality developments is known.
} 
academia and industry for many years now. Yet no satisfactory solution could be identified since the actual randomness of mortality seems to be too complex. In addition, trends and findings thought to be well-fitting have occasionally turned out to be changing over time. However, for the subsequent simulation of mortality a specific choice has to be made. In particular, the PML extension of the Lee-Carter model (cf. Section 1) will be used for the reason of its widespread acceptance, the apparent robustness, and its relatively easy implementation. It is well understood, though, that there are alternative choices and that certain shortcomings have been discussed in the literature. Yet, the drawbacks and restrictions do not seem to outweigh the mentioned advantages.

Naturally, the mentioned restrictions place a caveat on the entire analysis and thus obtained results as a far more complex reality will ultimately also influence results. This is especially true for e.g. investment risk or potential basis risk due to regulatory provisions regarding admissible choices. However, further insight and a general direction regarding the advantageousness of risk avoidance through offering mortality-indexed annuities is expected instead.

\subsection{Simulation of Mortality}

To account for the true insurance character of an MIA where aggregate longevity risk is retransferred to policyholders (or not transfered to the insurer at all), its individual form is explicitly included in the simulation. That way not only does the general average mortality underly random influences but also each individual's lifetime. Put in different words, there is also risk for each insured that his or her individual lifetime deviates from an initial expectation.

What can be considered a "background risk" here is the fluctuation of the overall mortality pattern. More precisely, future mortality is assumed to develop according to the LC/PML model. The vast majority of contributions have fitted the LC/PML model to actual data determining an ARIMA $(0,1,0)$ model as most suitable to describe the $\left\{\kappa_{t}\right\}$ time series. This effectively means that at any point in time $t$ a linear extrapolation from the current level of $\kappa_{t}$ is the best estimate (denoted as $\left.\hat{\kappa}_{t}\right)$. ${ }^{27}$ and it will also be met on average under the present assumption 28

Of course, this is only true due to the fact that model uncertainty is excluded from the present investigation. Instead, it is assumed that it is a priori known which model underlies the random future mortality paths. Thus, there should not be any objections to basing best estimates for the mortality index $\left\{\kappa_{t}\right\}$ at future times $t$ on the same drift or trend initially determined when calibrating the LC model.

When transferring the proposed product to real annuity markets an additional source of uncertainty may be the question of whether structural changes have occurred or will be occurring to the mortality patterns applicable to the portfolio of contracts under consideration. While especially the latter question could only be answered when drawing upon epidemiological, medical, or even philosophical input, the former challenge can be met easily with a reestimation (or recalibration) of the LC model to both historical data as well as actual mortality experience between times 0 and $t$. Thus, forecasts from time $t$ on could be improved compared to

\footnotetext{
${ }^{27}$ Note that there is no distinction in the notation between a best estimate $\hat{\kappa}_{t+1}$ made at time $t$ for the year after next and $\hat{\kappa}_{t+1}$ as a best estimate made at time $t+1$ for the period just begun. However, from the context it should always be clear at what time the respective estimate has been made so that e.g. an additional subscript appears dispensable.

${ }^{28}$ For the remainder of the present part a tilde above a random variable symbol $\sim$ shall denote actual realizations, whereas a hat symbol $\stackrel{r}{*}$ is to indicate projections or forecasts of that random variable.
} 
just a periodic update. In the present context, this is not necessary due to the exclusion of model uncertainty, and as this would also drastically increase the computational complexity, a reestimation of model parameters is dismissed here.

However, the disturbance terms from the ARIMA model cause uncertainty about the actual realizations $\tilde{\kappa}_{t}{ }^{29}$ This can also be interpreted in a way that at each point in time $t$ nature draws from the spectrum of possible mortality developments which in expected terms meets the previous best estimate $\hat{\kappa}_{t}$. More specifically, it is assumed that at any future time $t$ the uncertainty can be expressed as $\tilde{\kappa}_{t}=\hat{\kappa}_{t}+\tilde{\eta}_{t}$ with $\eta_{t} \sim N\left(0, \sigma_{\kappa}^{2}\right)$. Thus, the larger the time horizon the larger the (accumulative) uncertainty about realizations $\tilde{\kappa}_{t}$ so that also uncertainty accumulates the more distant future central death rates are.

The individual form of uncertainty about a person's lifetime is incorporated into the simulation of the proposed product, and we shall briefly comment on this idea. Given an actually realized level of general mortality as outlined before, the result of surviving for another year (from time $t$ to $t+1$ ) or passing away is modeled as the result of a Bernoulli "experiment". The "population size" in this experiment is identical to the number of survivors alive at time $t, l_{x+t}$, and its "success" probability is $\hat{p}_{x+t}$ as determined by the overall (randomly sampled) mortality implied by $\tilde{\kappa}_{t}$.

Put in different words, as seen from time $t$ the actual number of survivors $\tilde{l}_{x+t+1}$ at time $t+1$ is a random sample from the binomial distribution $\operatorname{Bin}\left(l_{x+t}, \hat{p}_{x+t}\right)$. However, $\hat{p}_{x+t}$ is only a best estimate for the yet unknown realization of $p_{x+t}$ which itself is subject to the (immediate) draw of nature. The uncertainty about the actual number of survivors is even stronger for more distant points in time $t+k$ where also $l_{x+t+k-1}$ is unknown and has to be replaced by a best estimate $\hat{l}_{x+t+k-1}$.

Note also that the uncertainty about realizations of $\left\{\kappa_{t}\right\}$ accumulates over time in the sense that more future values of $\kappa_{t}$ are less predictable. This is due to the fact that at each intermediate point in time $i=0, \ldots, t$ nature "draws" realizations of the disturbance terms $\eta_{i}$ that all accumulate up to time $t$. Effectively, the distribution of $\kappa_{t}$ is thus more dispersed for longer time horizons $t$. As the adjustment mechanism proposed for the mortality-indexed annuities leads to both higher and lower benefits $F V_{t}$ at future times $t$ since deviations from the expected number of survivors in either direction can occur, the increasing dispersion of the time index $\left\{\kappa_{t}\right\}$ directly translates also into an increasing dispersion of future benefits $\left\{F V_{t}\right\}$.

As pointed out, the present model assumes a random nature of mortality that is twofold: neither the underlying general pattern is certain nor whether and to what extent individual lifetimes deviate from the general levels. Obviously, by this choice both aggregate and individual longevity are incorporated in the model. However, with the proposed possibility for adjustments to $\left\{F V_{t}\right\}$ at any time $t$ based on the equivalence principle as per (3.6) and resorting to the best estimates at that time, the insurer offsets the risk that actual mortality deviates from the projected (overall) trend. In this sense, the proposed mortality-indexed annuity is always balanced from the insurer's perspective. No deficit nor surplus is generated, and no defaults are to be expected.

29 Hanewald et al. (2009) point out that it may be sufficient to concentrate on uncertainty arising from the ARIMA process adapted to the $\left\{\kappa_{t}\right\}$ time series while the majority of previous contributions have ignored the error term. They also note that Lee and Carter (1992, Table B2) themselves noted that the former disturbance terms account for roughly $90 \%$ of standard errors of age-specific death rate projections. 


\subsection{The Benchmark: Conventional Life Annuities}

While annuity providers - as pointed out earlier - might generally be interested in the idea of not having to bear the aggregate longevity risk in mortality-indexed annuities (MIA), it still remains to be discussed how an assessment of the degree of advantageousness of these products can be made. More precisely, the deduction of a suitable measure has not yet been clarified.

Acknowledging that MIA do not yet exist and that the starting point for considering such innovation will necessarily be a conventional life annuity, it seems worthwhile to parallel the key financial figures from MIA with those from conventional products when exposed to the same mortality experience. In brief, a conventional annuity does not provide a possibility for the provider to adjust benefits in any fashion since those have to be set in fixed, nominal terms at the contract inception as per (3.2). Thus, dependent on how actual mortality within the portfolio under investigation realizes during the contract term, the reserve at the beginning of the $T$-th period (i.e. at time $T-1$ ), denoted by $V_{T}^{*, \text { conv }}$ may turn out to be insufficient or not and will thus result in either positive or negative values.

In general, two different approaches of modeling the case of insufficient policy reserves could be followed. Firstly, as is the case in the present paper, if during the contract term the reserve $V_{t}$ becomes negative it could be assumed that such deficit can be financed at the (unique) interest rate $i$ that was applied for discounting, e.g. in (3.3). An immediate justification for such a choice could be a requirement for the insurer imposed and enforced by the regulator to unconditionally fulfill contractual obligations. This way, policyholders would always received the benefits stipulated in their annuity contracts. Of course, to reflect higher refinancing costs and to introduce frictions in the capital market, an increased rate $i^{*}>i$ could additionally be incorporated. Secondly, insurer defaults could be assumed for the case that due to adverse longevity development the per-contract reserves are insufficient to cover an additional annuity payment to the surviving cohort members at some point in time. Only a reduced annuity payment could be paid to the policyholders then, and for the remainder of the contract term no further payments would be made. Effectively, the insurer would never have to make deficits but rather have a possibility to close down the particular portfolio. Contrarily, policyholders would bear the risk of default or the insurer's suspension of payments, and this aspect would imply further deliberations with respect to the comparability of mortality-indexed annuities and a thus modeled benchmark product. However, guaranteed lifelong payments through an insurer's obligation to make deficits are assumed for the remainder of this paper.

\section{Conventional Annuities under Aggregate Longevity Risk}

The exact distribution of final reserves $V_{T}^{*, \text { conv }}$ in conventional annuities is not yet known since it depends on the realized number of survivors in the portfolio of initially $l_{x}$ contracts, and those numbers fluctuate around the initial best estimates similar to the time series $\left\{\kappa_{t}\right\}$ as discussed above. However, annuity benefits $F V_{0}$ are determined as per 3.2 in a way that if actual mortality exactly follows the initial projection no surplus nor deficit in final reserves is possible, i.e. the annuity benefits thus determined are actuarially fair. The fact that the disturbance terms causing uncertainty in the LC/PML model are symmetric implies that best estimates are met on average. Thus, losses and profits in per-policy reserves at time $T$ can be expected with an equal chance. Even though it has to be kept in mind that this is seen from a (net) actuarial perspective, it is obvious that this represents a major disadvantage for the annuity provider. It is thus quite likely that the insurer would not want to accept such a high level of risk of insufficiently funded contracts and thus might aim at reducing 
the exposure to a "safe" level. It is self-evident that complete safety in the sense that no actuarial deficits in reserves are possible cannot be attained. However, it is reasonable that the annuity provider in charge of offering the benchmarking conventional life annuities would want to reduce the "shortfall" (or deficit) risk from $50 \%$ substantially, and this can most easily be achieved by incorporating a safety loading into the annuity calculation. More precisely, annual benefits are reduced by a certain amount which in turn accumulates to soothe the high deficit risk to acceptable levels. To facilitate a true comparison of MIA with conventional annuities, a specific exception from a net actuarial calculation must therefore be made to reflect the insurer's perspective as otherwise MIA would be compared to a product which is likely to never exist. Of course, regulatory requirements may also limit the range of actual choices in annuity markets, and this must also be kept in mind.

In terms of the distribution of $V_{T}^{*, \text { conv }}$, a simple way to achieve a reduction of the shortfall risk from $50 \%$ to an acceptable lower level of $\alpha$ consists in a right-shift of the entire distribution, and this can be done by building up contingency funds $\Delta_{\alpha, T}$ to increase the per-policy reserve.

To build up the additional amount of $\Delta_{\alpha, T}$ by the beginning of year $T$ (or at time $T-1$ ), the insurer will likely include a certain premium surcharge or safety loading. As in the present case an identical single upfront premium is considered for both the MIA and the benchmark product, this is achieved by adjusting the benefits. More precisely, the initially determined face value $F V_{0}$ is reduced to $F V_{0}^{\alpha} 30$

However, it is not a trivial task to determine the necessary adjustment. Its exact amount has an influence on the evolution of the per-contract reserves of the benchmark product when including this safety loading. Thus it is not conducive to establish as contingency funds that has to be accumulated by time $T-1$ e.g. a certain quantile of the original distribution of the reserves. The problem is that due to fluctuating mortality it can only be accumulated on average, and the transition from $F V_{0}$ to $F V_{0}^{\alpha}$ alters the distribution of reserves from $V_{T}^{*, \text { conv }}$ to $V_{T, \alpha}^{*, \text { conv }}$ so that the intended effect is not necessarily met ${ }^{31}$

Since a closed form expression of the actual amount of $F V_{0}^{\alpha}$ cannot be obtained, the insurer has to determine it e.g. by using a simulation study similar to the one presented in Section 4 in a way that reduces the frequency of deficits to the desired level of $\alpha$.

The thus adjusted benefit ${ }^{32} F V_{0}^{\alpha}<F V_{0}$ can be considered basically the original benefit $F V_{0}$ determined by $(3.2$, but from each payment a certain fixed amount is deducted. This difference can also be considered a recurring premium the insurer charges or retains to finance the ultimate contingency funds. Or, put differently, the insurer only sells conventional life annuities if at the same time an insurance savings scheme towards an ultimate financial cushion is embedded in the contract.

\footnotetext{
${ }^{30}$ As implied by the notation, it is of course subject to the admissible likelihood of actuarial losses $\alpha$ chosen to determine $\Delta_{\alpha, T}$

${ }^{31}$ To reflect the fact that the latter expression is related to the (reduced) face value of $F V_{0}^{\alpha}$ the additional subscript $\alpha$ is added to the symbol for the per-contract reserve for the benchmark product.

${ }^{32}$ Note that this benefit is not adjusted to actual mortality experience like $F V_{t}$ in MIA.
} 
This thought can be expressed more formally in expected terms as

$$
\begin{aligned}
\pi_{0} & =\sum_{k=0}^{T-1}\left\{F V_{0} \cdot{ }_{k} \hat{p}_{x} \cdot v^{k}\right\} \\
& =F V_{0} \cdot \ddot{a}_{x: T}^{1} \quad \text { see } 3.1 \\
& =\sum_{k=0}^{T-1}\left\{F V_{0}^{\alpha} \cdot{ }_{k} \hat{p}_{x} \cdot v^{k}\right\}+\Delta_{\alpha, T} \cdot v^{T-1} T-1 \hat{p}_{x} \\
& =F V_{0}^{\alpha} \cdot \ddot{a}_{x: T}^{1}+\Delta_{\alpha, T} \cdot{ }_{T-1} E_{x}
\end{aligned}
$$

In the last expression of (3.7), ${ }_{T-1} E_{x}$ is a (T-1)-year pure (unit) endowment insurance for a person aged $x{ }^{33}$ By comparing (3.1) and (3.7) the adjusted face value $F V_{0}^{\alpha}$ can be determined from the non-adjusted value $F V_{0}$ through

$$
\begin{aligned}
F V_{0} \cdot \ddot{a}_{x: T}^{1} & =F V_{0}^{\alpha} \cdot \ddot{a}_{x: T}^{1}+\Delta_{\alpha, T} \cdot{ }_{T-1} E_{x} \\
\text { so that } \quad F V_{0}^{\alpha} & =\frac{F V_{0} \cdot \ddot{a}_{x: T \mid}^{1}-\Delta_{\alpha, T} \cdot T-1}{\ddot{a}_{x: T}^{1} E_{x}} \\
& =F V_{0}-\frac{\Delta_{\alpha, T} \cdot T-1}{\ddot{a}_{x: T}^{1}} \\
& =F V_{0}-\Delta_{\alpha, T} \cdot \ddot{s}_{x: T}^{1}
\end{aligned}
$$

where $\ddot{s}_{x: T}^{1}$ is the actuarial accumulated value at time $T$ contingent on survival that corresponds to the same unit annuity underlying the actuarial present value $\ddot{a}_{x: T}^{1}$.

At this point the question may arise of whether one should also consider the per-policy reserves at any intermediate point in time $t$ when accounting for the risk of adverse mortality developments. Obviously, an insurer offering conventional annuities would not be willing to accept net deficits at those points in time either. For an answer, two important features of the comparable conventional annuities underlying the present investigation have to be kept in mind.

Firstly, if for any actual mortality development the reserve is negative at some intermediate point in time, it was assumed that the annuity provider may finance this shortfall at the same fixed interest rate $i$ that was assumed as the minimum guaranteed interest rate; cf. also the remarks on defaults in Subsection 3.3. Although external funds raised on capital markets will mostly not be available at such a low rate, this notion appears more realistic when considering the possibility that a shortfall may also be financed by borrowing against some other line of business or portfolio of contracts within the same insurance company. However, a choice of $i^{*}>i$ could also be considered ${ }^{34}$ As a further remark on this issue, note that reserve values analyzed are entirely based on a net actuarial assessment, i.e. except for the safety loading discussed above they do not include any further loadings or surcharges, and the investment

${ }^{33}$ Note that the last annuity payments are due at time $T-1$ so that it is sufficient to analyze the provider's financial situation at that time, and this corresponds to the fact that $V_{T}^{*, \text { conv }}$ is determined at that time as well.

${ }^{34}$ Note that for the subsequent simulation study, this alternative assumption produced results that only marginally differed, and for this reason it will not be further investigated. 
yields in excess of the interest rate $i$ are also not accounted for at this point so that in reality it is likely that actual per-policy reserves are higher in tendency and deficits less likely and less severe.

Secondly, and more importantly, it is to be noted that the risk of insufficient reserving is monotonous or increasing over time. It is easy to see that once in deficit, reserves are either only further diminished by subsequent annuity payments or additionally inflated to a greater or lesser extent due to interest and the inheritance effect. However, the latter only reduce or reinforce the deficit, but will never change a negative reserve back into a surplus.

As an alternative way of achieving a significant reduction of the insurer's actuarial shortfall risk in the benchmarking product, loading factors incorporated in life tables that are common in the industry could be applied in the calculation of the "comparable" results. Those are included in the tables when transiting from "second order", i.e. "raw", mortality data to "first order" values used for pricing and reserving.

Another issue that has not been further discussed so far is the fact that on average there is no actuarial profit or loss when using the unadjusted $F V_{0}$. By including the safety loading, the additional contingency funds $\Delta_{\alpha, T}$ per surviving policyholder accumulated over the contract period further improves the financial situation, and the effective risk of net deficits has been reduced to $\alpha$. The resulting considerable expected profits for the benchmarking conventional annuities, which take on positive values with a probability of $1-\alpha$, arise entirely from mortality fluctuations. This is due to the fact that it was assumed here that the insurer does not generate higher investment yields than the constant interest rate $i$ and that no costs or expenses are accounted for. A straightforward argument would then be that surplus reserves - if any - have arisen entirely from the portfolio's mortality exposure and thus "belong" to the policyholders. While this argument may not be novel, the idea of actually sharing surplus from "mortality (or risk) gains" is at least new in the German insurance market. Only recently, German legislation has set off the surplus generated by "mortality gains" and "cost gains". which have long been treated differently than "investment gains" on policy reserves. Of the latter at least $90 \%$ had been required to be credited to policyholders, and now at least $75 \%$ and $50 \%$ of surplus from the two previously mentioned sources, respectively, are required to be attributed to individual policies 35

Now, as in the present contribution the entire surplus (or deficit) in the final per contract reserves is only due to "mortality gains", the largest extent of profit sharing would be to attribute the ultimate reserve completely to the surviving policyholders as a terminal bonus. Naturally, this would leave the insurer with a certain result of zero, and it does not seem to be too unrealistic given that no further costs or expenses are included in the present model. This is exactly the same situation as for the mortality-indexed annuities focused on earlier, and it is an open question whether a safety loading would be required at all. Effectively, only the mechanism of how mortality fluctuations due to aggregate longevity risk are borne by the policyholders is different now compared to MIA 36

An intuitive objection to this idea is related to the cases where the ultimate reserves are negative, i.e. development of mortality that render the previous calculations insufficient. It is

${ }^{35} \mathrm{Cf}$. also the remarks on regulatory provisions regarding profit sharing in Germany in Footnote 8 on $\mathrm{p} 5$ An abundant number of previous contributions have also discussed or analyzed profit-sharing, and for the specific case of Germany cf. e.g. Schwintowski and Ebers (2002), Ebers (2001), or Gruschinske (1989).

36 As a specific measure for the advantageousness of MIA is proposed only later, note at this point that in expected terms such a complete transfer of ultimate reserves in the benchmarking conventional annuity yields exactly the same results as for the MIA. 
highly debatable whether in any insurance market negative reserves, i.e. deficits, would ever be borne by the policyholders and how an insurer could collect this amount if necessary. Given the high age of the "unfortunate" survivors this thought seems even more questionable and it thus seem reasonable if at least negative reserves would be borne by the insurer. Of course, this would greatly improve the benchmark product from the policyholders' point of view, ${ }^{37}$ and the insurer would certainly include a safety loading to reduce the risk of deficits that cannot be passed on to the insureds.

Referring to the above remarks on profit sharing related to "mortality gains", which have long not been credited to policyholders at all, a compromise between the two extremes discussed could consist in attributing only a certain share $X(0<X<1)$ of ultimate reserves - if they are positive - to survivors as terminal bonuses under the benchmark product. This way, policyholders participate to a greater or lesser extent in surplus due to mortality fluctuations but do not have to cover deficit scenarios, which would seem rather unrealistic. On the other hand the insurer, who might not be willing to completely cede positive reserves, retains at least the remaining fraction of $(1-X)$ of positive surplus reserves, and the risk of deficit reserves is to $\alpha$ when including a safety loading as discussed above.

For the subsequent analyses, a value of $X=0.75$ will be assumed as this reflects the minimum required level of (mortality) surplus participation in Germany. More formally, at time $T-1$, surviving policyholders do not only receive an annuity payment in the amount of $F V_{0}^{\alpha}$ but also a terminal bonus of $X \cdot \max \left\{0 ; V_{T, \alpha}^{*, \text { conv }}\right\}$ An alternative choice of $X=0.90$ has also been considered, thus mirroring the respective minimum level related to investments according to German regulation. Despite differences in the particular values, the overall tendency of results presented in Section 4.2 still applied.

\section{Comparing Mortality-Indexed Annuities and Conventional Annuities}

It is more than obvious that a MIA would be (dis-)advantageous compared to a conventional life annuity exactly when it provides higher (lower) benefits at any given future time. However, due to the fluctuations of mortality (and consequently also of adjusted benefits $F V_{t}$ ) it is not clear how often and to what extent the benefits are higher than $F V_{0}^{\alpha}$ in a comparable conventional annuity - provided that the latter includes contingency funds as discussed above. Note that with certainty $F V_{0}>F V_{0}^{\alpha}$ but that no definite statements are possible as to $F V_{t}$ for future points in time. The standard assumption of risk-averse policyholders is ignored in this context. In a further analysis the fact that risk-averse individuals being reluctant to not transfer the aggregate longevity risk could also be incorporated when determining to what extent MIA are advantageous compared to conventional products. In tendency, the excess of MIA benefits $F V_{t}$ over $F V_{0}^{\alpha}$ is diminished by the increase in risk to be borne by the policyholder. Overall effects are thus likely to be highly dependent on the degree of individual risk aversion.

What also needs to be kept in mind is the fact that for most policyholders sooner benefits in excess of "conventional" benefits should have a stronger weight than those in the more distant future. Discounting should reflect such time preferences, and as it is also less likely for each insured to actually live to see such late excess benefits, "mortality discounting" should be incorporated through the concept of actuarial present values; cf. (3.3).

Following the overall principles governing actuarial calculation in life and pension insurance, it thus seems worthwhile to further analyze the actuarial present value of the difference in MIA

37 Anticipating the results from the simulation presented in Section 4.2 the proposed MIA are disadvantageous on average when compared to such an alternative benchmark product. 
benefits compared to conventional annuities as seen from time $t=0$ from the policyholders' perspective. One should expect that if the fluctuations of adjusted benefits $\left\{F V_{t}\right\}$ do not turn out to be overly downward drifting (below the level of $F V_{0}^{\alpha}$ ) and/or if this only occurs in the more distant future, then the initially higher level of $F V_{0}$ in comparison to $F V_{0}^{\alpha}$ combined with a higher likelihood for each insured to actually receive the earlier benefits at all and sooner are likely to prevail. As a direct consequence, the mentioned "actuarial present value of MIA excess benefits", denoted by $A D V_{\text {MIA }}^{\alpha}$ below, will become positive, thus being in line with the notion of a measure of advantageousness.

Note that the proposed measure $A D V_{\text {MIA }}^{\alpha}$ can generally also be obtained directly from the ultimate per-contract reserves as the respective average across all simulation paths, discounted to time $t=0$ and reflecting the fact that only $\tilde{l}_{x+T-1}$ survivors have actually survived to the end of the contract term. However, this is only true if no terminal bonus is included for the benchmark product in the measure of advantageousness. In that case, both $A D V_{\text {MIA }}^{\alpha}$ and the "average discounted final reserve" exactly coincide. Yet, by accounting for a surplus participation mechanism as outlined before, the two measures need not coincide, and in fact $A D V_{\text {MIA }}^{\alpha}$ as given below rather expresses the advantageousness of a MIA contract from the policyholders' point of view, accounting for the entire potential cash flow. Contrarily, the corresponding "average discounted final reserve" is exactly what is left for the insurer if it is reduced by the mentioned terminal bonus.

Technically, for each scenario in the Monte-Carlo simulation the amount

$$
\begin{aligned}
A D V_{\text {MIA }}^{\alpha}= & \sum_{k=0}^{T-1}\left\{\left(F V_{k}-F V_{0}^{\alpha}\right) \cdot{ }_{k} \tilde{p}_{x} \cdot v^{k}\right\} \\
& -X \cdot \max \left\{0 ; V_{T, \alpha}^{*, \text { conv }}\right\} \cdot{ }_{T-1} \tilde{p}_{x} \cdot v^{T-1} \\
= & \sum_{k=0}^{T-2}\left\{\left(F V_{k}-F V_{0}^{\alpha}\right) \cdot{ }_{k} \tilde{p}_{x} \cdot v^{k}\right\} \\
& +\left(F V_{T-1}-\left(F V_{0}^{\alpha}+X \cdot \max \left\{0 ; V_{T, \alpha}^{*, \text { conv }}\right\}\right)\right) \cdot{ }_{T-1} \tilde{p}_{x} \cdot v^{T-1} \\
= & \sum_{k=0}^{T-1}\left\{\left(F V_{k}-F V_{0}^{\alpha}\right) \cdot \tilde{l}_{x+k} / \tilde{l}_{x} \cdot v^{k}\right\} \\
& -X \cdot \max \left\{0 ; V_{T, \alpha}^{*, \text { conv }}\right\} \cdot \tilde{l}_{x+T-1} / \tilde{l}_{x} \cdot v^{T-1}
\end{aligned}
$$

is computed where actual survival rates ${ }_{k} \tilde{p}_{x}=\tilde{l}_{x+k} / \tilde{l}_{x}$ are used. Note that $A D V_{\text {MIA }}^{\alpha}$ now actually includes the discussed terminal bonus for the benchmark product, which can directly be seen in 3.10 .

It is interesting at this point to briefly discuss the hypothetical case mentioned earlier in the first place. If the entire ultimate reserve $V_{T, \alpha}^{*, \text { conv }}$ was transferred to the surviving policyholders both in the case of positive and negative values ${ }^{38}$ note that the expected value of $A D V_{\text {MIA }}^{\alpha}$ would be zero as well as the average discounted $V_{T, \alpha}^{*, \text { conv }}$ from the insurer's point of view. This clearly demonstrates that no added value is created just by designing and offering the mortality-indexed annuities.

However, the asymmetric surplus sharing mechanism incorporated in (3.11) leads to quite different degrees of advantageousness for policyholders and the insurer, and eventually both

38 This would be the case if in 3.11 the last expression $X \cdot \max \left\{0 ; V_{T, \alpha}^{*, \text { conv }}\right\} \cdot \tilde{l}_{x+T-1} / \tilde{l}_{x} \cdot v^{T-1}$ were replaced by $V_{T, \alpha}^{*, \text { conv }} \cdot \tilde{l}_{x+T-1} / \tilde{l}_{x} \cdot v^{T-1}$. 
have to ponder the downside risk, the upside potential, and the uncertainty about the exact outcomes. For this purpose, the empirical distribution of $A D V_{\text {MIA }}^{\alpha}$ will be further analyzed in the following section.

\section{Simulation and Results}

\subsection{Data and Parameterization}

To perform the simulation of key financial figures (and especially the measure for advantageousness from the policyholders' perspective $A D V_{\text {MIA }}^{\alpha}$ ) for the mortality-indexed annuities proposed in Section 2.5, several particular choices in terms of data and parameterizations have to be made. Those will be detailed and motivated in the present section.

Firstly, since the simulation intends to investigate variations in the mortality (or longevity) within a stylized homogeneous portfolio of insured and the respective implications for the adjustments of MIA benefits, it is self-evident that the selection effect of (generally lower) annuitant mortality versus the general population mortality should be accounted for. Thus, due to the limited availability of such annuitant mortality data, the present simulation resorts to a data set for the UK provided by the CMI ${ }^{39}$ This ultimately led to the LC time index $\left\{\kappa_{t}\right\}$ being modeled as an ARIMA $(0,1,0)$ time series, thus being in line with previous research.

Secondly, since there are more male annuitants than females in the mentioned data set it will be assumed that the homogeneous cohort under investigation is composed of males exclusively. A limited number of years covered by the data also forces to base the calibration (or parameter estimation) of the LC/PML model on calendar years $z=1983, \ldots, 2003$. Consequently all projections begin in year $z=2004$ which corresponds to time $t=0$. Although for calibration purposes only ages $x=25, \ldots, 110$ could be considered, the cohort's initial age is assumed to be $x=60$ at time $t=0$, and the annuity term here is limited to $T=41$ at the outset. Thus, the last annuity payment is due at the beginning of the year $y=2044$ (or at time $t=40$, equivalently) where all surviving cohort members have just completed their $100^{\text {th }}$ birthday with no further payments thereafter. However, ultimate financial data such as per-policy reserves can also be considered in the "second" after the last annuity payment at time $T-1$ since no further cash flows are to occur for the remainder of the $T$-th year. This is simply owed to the fact that an annuity immediate was assumed here, which makes payments in advance.

Lastly, the upfront premium considered to be exogenously given is set as $\pi_{0}=100,000,40$ and the number of generated scenarios in the Monte-Carlo simulation is set to $N=10,000$ throughout the subsequent analyses 41

39 The Continuous Mortality Investigation Bureau (CMI) is an institution sponsored by the Faculty of Institute of Actuaries in the UK in charge of fostering research related to mortality modeling issues. Data provided encompasses annuitant mortality data per capita from the British insurance industry.

40 To illustrate the notion of a fixed upfront premium in the amount of $\pi_{0}$ it may be helpful to consider a pre-existing individual savings plan, a term life insurance ending exactly at the annuity inception date, or an inheritance made by the insured. In either case proceeds from these financial instruments become available at time $t=0$ exactly in the amount of $\pi_{0}$. An additional assumption could be that the annuity provider cannot ask the policyholder to pay a higher upfront premium in order to establish contingency funds, but accordingly needs to make adjustments to the initial annuity face value, i.e. provide only $F V_{0}^{\alpha}$ instead of $F V_{0}$.

${ }^{41}$ A precise notation would require to add a symbol $j$ to the formula symbols introduced in this contribution to denote that they differ by scenario. For the sake of clarity, such notation has been ignored so far and will only be used below if explicitly necessary. 
The above outlined parameterization choices are summarized in Table 1 .

Table 1: Parameterization for the Simulation of MIA Advantageousness

\begin{tabular}{|c|c|c|c|c|}
\hline number of scenarios & initial age & annuity term & single premium & surplus share \\
\hline$N$ & $x$ & $T$ & $\pi_{0}$ & $X$ \\
\hline 10,000 & 60 & 41 & 100,000 & 0.75 \\
\hline
\end{tabular}

Two parameterization choices have not yet been further discussed. For the size of the fictitious portfolio, i.e. the initial number of insured, two different choices are considered: On the one hand, to reflect comfortable diversification effects, a relatively large portfolio is assumed by setting $l_{60}=100,000$. On the other hand, individual fluctuations of lifetime are modeled as Bernoulli experiments with the actual number of survivors being random samples from suitably parameterized distribution. Given the Law of Large Numbers, which states that sample means will converge to the theoretical "true" mean of the underlying distribution upon increasing sample sizes, it is likely that thus randomly sampled numbers of survivors will be relatively close to the respective overall survival probabilities "drawn" by nature. To challenge individual fluctuations to a larger extent and also accounting for the fact that in reality (primary) insurers may only be able to compose smaller homogeneous annuity portfolios, an alternative portfolio size of $l_{60}=1,000$ is also considered.

For the constant interest rate $i$ incorporated into the calculation of actuarial present values $\ddot{a}_{x: T \uparrow}^{1}$ and discounting purposes two different assumptions were made as well ${ }^{42}$ A quite conservative yet commonly found value of $i=3 \%$ p.a. is assumed as well as the more ambitious choice of $i=5 \%$ p.a. In the long run, with the use of long-term government bonds, insurers in many countries have been able to generate returns on their investments well above the former choice with only moderate effort to attain the latter level.43

Table 2 provides an overview of the portfolio size and interest rate combinations, including the abbreviations for the resulting "treatments" referred to below.

Table 2: Treatments in the Simulation of MIA Advantageousness

\begin{tabular}{c|c|c|c|}
\multicolumn{2}{c|}{} & \multicolumn{2}{c|}{$i$} \\
\cline { 3 - 4 }$l_{60}$ & 100,000 & $3 \%$ & $5 \%$ \\
\cline { 2 - 4 } & 1,000 & $A_{I}$ & $A_{I I}$ \\
\cline { 2 - 4 } & & $B_{I}$ & $B_{I I}$ \\
\hline
\end{tabular}

For the admissible shortfall risk $\alpha$ values of $0.001,0.005$, and 0.01 are used to reflect reasonable choices not uncommon in the industry. If necessary for distinction, the specific values will be added as a superscript as e.g. in $A D V_{\mathrm{MIA}}^{0.001}$.

${ }^{42}$ Note that the present analysis is made from a net actuarial standpoint where actual (excess) yields on the invested reserves are disregarded. As discussed above, an adequate mechanism for redistribution of (investment) surplus must be thoroughly considered.

43 See also Kling et al. (2007) for a thorough analysis of the effects on risk exposure that different regimes of surplus distribution as related to investment yields being in excess of interest rate guarantees. 


\subsection{Results and Discussion}

When applying the parameterization and underlying data outlined in Section 4.1 to the MonteCarlo simulation model introduced in Section 3.1, the data being computed is extensive: Four treatments with $N=10,000$ scenarios each were run, and in each run $j$, a series of MIA face values $\left\{F V_{t}^{j}\right\}_{t=0 . .40}$ was generated ${ }^{44}$ contingent on three different levels of $\alpha$-among other interim data necessary to actually compute the MIA developments.

Figure 1: Paths of MIA Benefits in Comparison to Conventional Annuity - Treatment $A_{I}$, $\alpha=0.005$

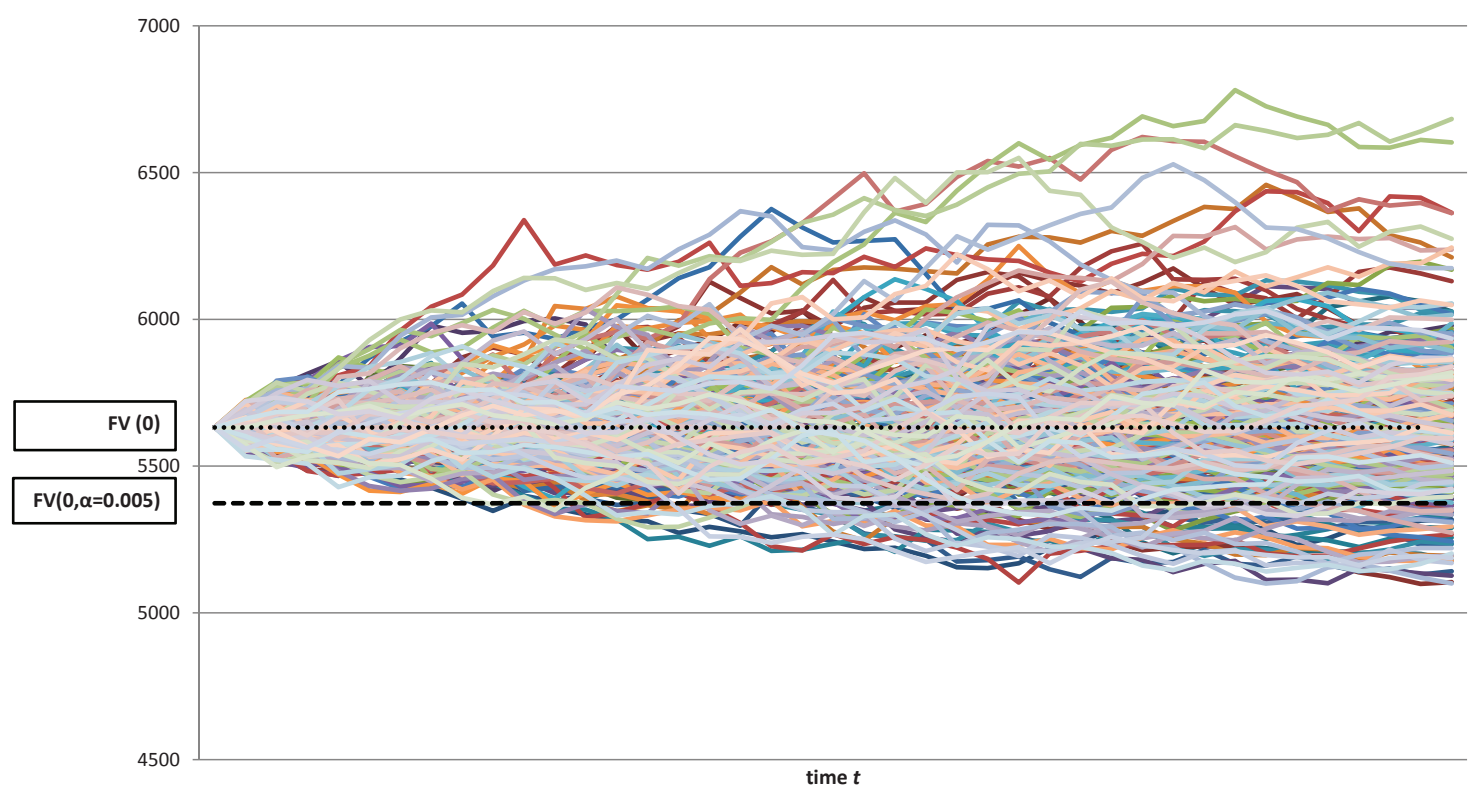

Source: authors' calculation, based on data provided by the CMI.

The dotted line ("FV(0)") indicates the annuity face value $F V_{0}=5,632$ prior to contingency funds inclusion; the dashed line ("FV $(0, \alpha=0.005)$ ") shows $F V_{0}^{0.005}=5,373.5$ for a comparable conventional annuity.

For instance, for the base case treatment using $\alpha=0.005$ Figure 1 depicts the spectrum of MIA benefit paths as well as those obtained from a comparable "conventional" life annuity - both with and without contingency funds. ${ }^{45}$ Obviously, it is next to impossible to directly assess this amount of data. While at first glance it may seem that paths tend to fall below the "conventional" benefit level (dashed, lower horizontal line) quickly 46 it has also to be kept in mind what was mentioned above in the context of deducing the measure for advantageousness. Benefits below that threshold in the not-so-near future can be assumed to be less grave due to discounting and mortality in the meantime. In addition, note that an annuity pays (accumulative) benefits at all times contingent on survival, i.e. rather the sum of excess or deficit benefits (or the area between each MIA path and the constant benefit of $F V_{0}^{\alpha}$ ) is a relevant quantity.

${ }^{44}$ Note that no payments are due after time $T-1$ so that no value of $F V_{41}$ needs to be determined.

${ }^{45}$ It is obvious and also evident from Figure 1 that for the latter case, benefits from the conventional product coincide with the initial MIA benefit that is determined for the very first period (and later revised), as at time $t=0$ the respective best estimates coincide as well.

${ }^{46}$ In fact, roughly half of values $F V_{40}$ are lower than the initial value $F V_{0}$ indicated by the dotted line in Figure 1 
As the interest and "survival" discounting cannot easily be captured when using visualizations similar to Figure 1, MIA face values are aggregated to realizations of $A D V_{\mathrm{MIA}}^{\alpha}$ as this measure includes the twofold discount of interest and mortality. This effectively leaves 120,000 values for further a analysis. The remaining complexity of the results can suitably be depicted by using histograms of the empirical distribution of $A D V_{\text {MIA }}^{\alpha}$, such as Figure 2 for different levels of $\alpha$ in the base case treatment $A_{I}$ and Figures 3,4 , and 5 for analogous representations for the other treatments $A_{I I}, B_{I}$, and $B_{I I}$, respectively. Further analysis of the distributions of $A D V_{\mathrm{MIA}}^{\alpha}$ is intended to answer the question whether the apparent attractiveness of MIA for insurers also applies to potential policyholders 47

\section{Treatment $A_{I}$ - the Base Case}

For the base case treatment $A_{I}$, the innovative mortality-indexed annuity turns out to be more advantageous than a conventional annuity in the vast majority of cases with truly disadvantageous scenarios in only few cases; see Figure 2, In fact, the MIA provides an average level of $A D V_{\text {MIA }}^{\alpha}$ of between roughly 1,050 and 1,350 - depending on $\alpha$. Given that $F V_{0}$ is 5,632, these values correspond to $19 \%$ to $24 \%$ of an annual benefit payment. For treatment $A_{I}$, these values (among a selection of risk measures) are listed in Table 3 separated by the insurer's shortfall risk $\alpha$. What can also be observed is the fact that the downside or "shortfall" risk $\mathbb{P}\left[A D V_{\text {MIA }}^{\alpha}<0\right]$ is iddentical to $\alpha 44^{48}$ Thus it is rather unlikely that the innovative product is truly disadvantageous. Obviously, the smaller $\alpha$, i.e. the smaller the insurer's admissible actuarial shortfall risk, the more advantageous are potential MIA benefits. This is simply due to the fact that a higher $\alpha$ requires $F V_{0}^{\alpha}$ to be lower, ceteris paribus, in order for the contingency funds $\Delta_{\alpha, T}$ to be available by time $T$.

Figure 2: Empirical Distribution of $A D V_{\text {MIA }}^{\alpha}$ - Treatment $A_{I}$
(a) $\alpha=0.001$
(b) $\alpha=0.005$
$F V_{0}^{\alpha}=5,373.50$
(c) $\alpha=0.010$
$F V_{0}^{\alpha}=5,330.00$
$F V_{0}^{\alpha}=5,393.50$
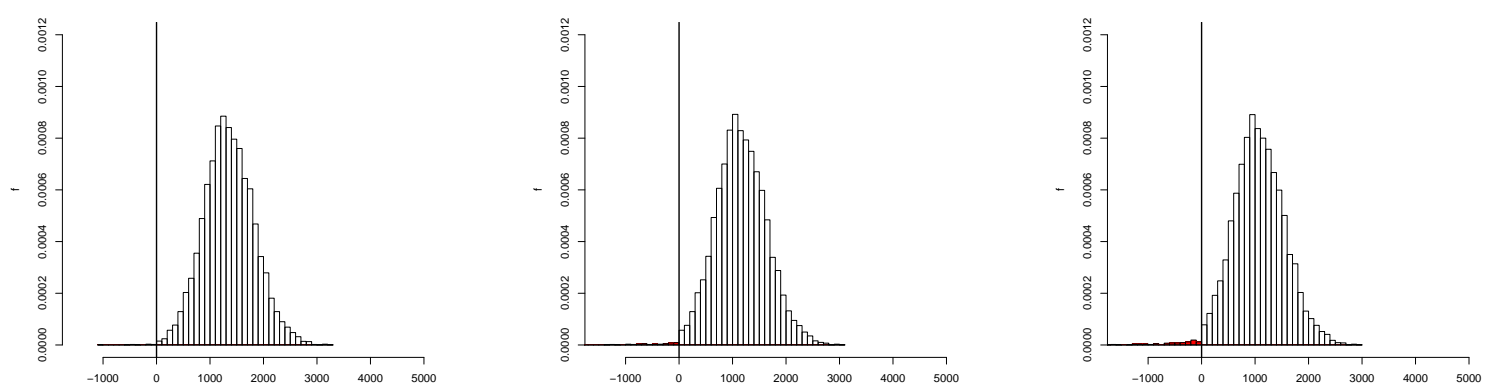

Source: authors' calculation, based on data provided by the CMI.

Another more general measure for the riskiness would be the variability of the (degree of) advantageousness. The empirical variances are therefore also listed in Table 3 , and apart from the fact that the actual differences in relative terms are quite small compared to their high levels, an increase of the variability can still be observed.

\footnotetext{
${ }_{47}$ Recall that $A D V_{\mathrm{MIA}}^{\alpha}$ was developed as a measure for the advantageousness of MIA in comparison to conventional life annuities - if only the insurer includes a safety loading to reduce the risk of deficit net reserves to $\alpha$.

${ }^{48}$ Of course, this is due to the design of the surplus participation accounted for in $A D V_{\text {MIA }}^{\alpha}$.
} 
Obviously advantageous scenarios are very likely while the policyholders' downside risk is limited to $\alpha$, but it is also interesting to further analyze how negative potential adverse scenarios may be. For this purpose, also the expected [policyholder] shortfall (or rather "expected MIA disadvantageousness") is computed, i.e. $\mathbb{E}\left[A D V_{\text {MIA }}^{\alpha} \mid A D V_{\text {MIA }}^{\alpha}<0\right]$. Those values provide an idea of the severity of waiving to transfer aggregate longevity risk to an annuity provider, and the respective quantities are also provided in Table 3. It is not surprising then that with a higher $\alpha$ (and thus also higher values of $F V_{0}^{\alpha}$ or smaller safety loadings) the general level of $A D V_{\mathrm{MIA}}^{\alpha}$ is lower, and consequently also expected shortfalls take on more negative values.

Table 3: Key Figures from Treatment $A_{I}$

\begin{tabular}{|l||r|r|r|}
\hline Annuity Benefits & $\alpha=0.001$ & $\alpha=0.005$ & $\alpha=0.010$ \\
\hline \hline$F V_{0}$ & $5,330.00$ & $5,373.50$ & $5,393.50$ \\
\hline$F V_{0}^{\alpha}$ & & \\
\hline \hline Risk Measure & $1,354.12$ & $1,159.54$ & $1,068.75$ \\
\hline $\mathbb{E}\left[A D V_{\text {MIA }}^{\alpha}\right]$ & 0.001 & 0.005 & 0.010 \\
\hline $\mathbb{P}\left[A D V_{\text {MIA }}^{\alpha}<0\right]$ & $220,915.5$ & $229,915.0$ & $238,233.3$ \\
\hline $\operatorname{Var}\left[A D V_{\text {MIA }}^{\alpha}\right]$ & -321.29 & -492.31 & -520.37 \\
\hline $\mathbb{E}\left[A D V_{\text {MIA }}^{\alpha} \mid A D V_{\text {MIA }}^{\alpha}<0\right]$ & -31.67 \\
\hline \multicolumn{4}{|c||}{ Source: authors' calculation, based on data provided by the CMI. }
\end{tabular}

A further question is the issue of marketability. More precisely, assuming that the insurer does not intend to (or, for reasons of competitiveness, may not) conceal the downside potential in MIA contracts, it is at least questionable how well it would be received by insurees despite its reduction to $\alpha$. Naturally, an immediate attractive counterargument can be brought forward: the (non-reduced) annuity benefit $F V_{0}$ that can be provided when policyholders agree to bear the aggregate longevity risk is initially higher than the comparable value of $F V_{0}^{\alpha}$.

An individual's risk perception, assessment, or willingness to bear longevity risk would also be an influencing factor related to this issue. For instance, individuals with worse than average health that would already have been driven out of typical annuity markets due to adverse selection might be very interested to enjoy this initial head start of MIA in comparison to the benchmark product since the latter might appear to be overpriced for them. Although certainly a further advantage of MIA, a detailed discussion is beyond the scope of this paper.

\section{Treatment $A_{I I}$}

When transiting to treatment $A_{I I}$, i.e. incorporating a higher interest rate of $i=5 \%$, a very general first observation is that the graphical representations in Figure 3 do not drastically differ from those of treatment $A_{I}$. However, on closer inspection it is also evident that the respective distributions of $A D V_{\text {MIA }}^{\alpha}$ are slightly more compressed without a higher shortfall risk. This is already revealed by Figure 3 but more so by the respective risk measures provided in Table 4

In particular, the empirical means are significantly reduced by roughly $225-280$ compared to treatment $A_{I}$ to levels of between 850 and 1,075 (see Table 4). Also, the expected shortfalls are smaller (in absolute terms) now, and these observations demand some further commenting.

Firstly, a higher interest rate primarily has an influence on the actuarial present values $\ddot{a}_{x: T \uparrow}^{1}$ which are lower compared to the case of $i=3 \%$ due to the stronger discounting; see 
Figure 3: Empirical Distribution of $A D V_{\mathrm{MIA}}^{\alpha}$ - Treatment $A_{I I}$
(a) $\alpha=0.001$
(b) $\alpha=0.005$
(c) $\alpha=0.010$
$F V_{0}^{\alpha}=6,679.05$
$F V_{0}^{\alpha}=6,725.70$
$F V_{0}^{\alpha}=6,743.45$
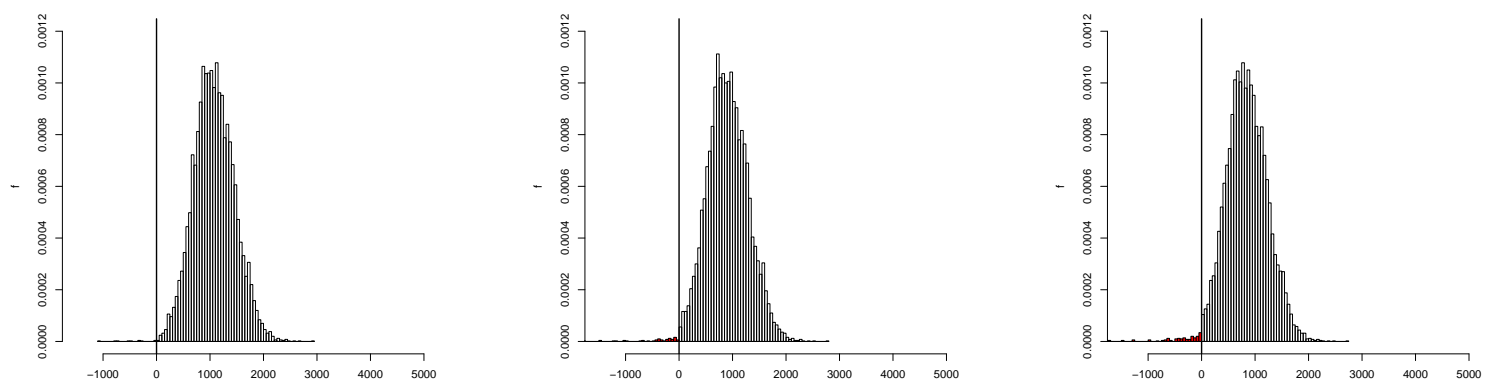

Source: authors' calculation, based on data provided by the CMI.

Table 4: Key Figures from Treatment $A_{I I}$

\begin{tabular}{|c|c|c|c|}
\hline Annuity Benefits & $\alpha=0.001$ & $\alpha=0.005$ & $\alpha=0.010$ \\
\hline$F V_{0}$ & \multicolumn{3}{|c|}{$6,975.56$} \\
\hline$F V_{0}^{\alpha}$ & $6,679.05$ & $6,725.70$ & $6,743.45$ \\
\hline \multicolumn{4}{|l|}{ Risk Measure } \\
\hline $\mathbb{E}\left[A D V_{\mathrm{MIA}}^{\alpha}\right]$ & $1,075.60$ & 907.29 & 842.33 \\
\hline $\mathbb{P}\left[A D V_{\mathrm{MIA}}^{\alpha}<0\right]$ & 0.001 & 0.005 & 0.010 \\
\hline $\operatorname{Var}\left[A D V_{\text {MIA }}^{\alpha}\right]$ & $142,381.3$ & $147,804.8$ & $152,138.2$ \\
\hline $\mathbb{E}\left[A D V_{\mathrm{MIA}}^{\alpha} \mid A D V_{\mathrm{MIA}}^{\alpha}<0\right]$ & -448.61 & -413.32 & -391.25 \\
\hline
\end{tabular}

(3.3). When inspecting (3.2), this obviously results in a higher level of $F V_{0}$ given that the upfront premium remains unchanged ${ }^{49}$ Similarly, in $(3.6)$ the higher interest rate results in higher annuity benefits $F V_{t}$ as the updated actuarial present values $\ddot{a}_{x+t: \overline{T-t}}^{1}$ are also increased. However, the effect on (3.5) is ambiguous. For the case of $t=1$, a higher value of $i$ obviously yields a higher value of $V_{1}{ }^{50}$ but for times $t>1$ both $V_{t-1}$ and $F V_{t-1}$ are higher compared to the base case so that a general statement on the evolution of per-policy reserves $V_{t}$ is not possible. Naturally, the claimed effect on (3.6) is rendered ambiguous.

For the benchmarking conventional annuity, rearranging (3.7) and taking into account that both $\ddot{a}_{x: T}^{1}$ and ${ }_{T-1} E_{x}$ are lower under a higher $i$ suggests that $F V_{0}^{\alpha}$ must be higher as again the upfront single premium $\pi_{0}$ is considered fixed, but this is also contingent on a constant value of $\Delta_{\alpha, T}$.

The described theoretically motivated effects on both $F V_{0}$ and $F V_{0}^{\alpha}$ can also clearly be identified in the first lines of Table 4 in comparison to the respective values in Table 3 . However, the difference between $F V_{0}$ and $F V_{0}^{\alpha}$ is lower now; for instance, in the case of $\alpha=0.001$ it is now only 296 instead of 302 units compared to treatment $A_{I}$. Therefore, a higher interest rate $i$

${ }^{49}$ Compare the remarks on this assumption in Footnote 40 on $\mathrm{p} 21$

${ }^{50}$ Recall that the initial reserve is identical to the upfront single premium, i.e. $V_{0}=\pi_{0}$. 
seems to work marginally in favor of the conventional annuity, where only a lower initial benefit adjustment from $F V_{0}$ to $F V_{0}^{\alpha}$ is necessary to incorporate the safety loading that accumulates to the desired contingency funds and thus reduces the insurer's shortfall risk to a given level of $\alpha$. Yet the (initial) levels of benefits for both the innovative MIA and the conventional product are considerably higher under a higher interest rate $i$.

Secondly, as the measure of advantageousness $A D V_{\text {MIA }}^{\alpha}$ is based on the actuarial present value of the difference between MIA benefits evolution and the comparable conventional benefits $F V_{0}^{\alpha}$, 3.11 reveals that discounting with a higher fixed interest rate $i$ also has an influence. Obviously, when increasing $i$ from $3 \%$ to $5 \%$ the stronger discounting through a lower discounting factor $v$ causes $A D V_{\text {MIA }}^{\alpha}$ to be lower ceteris paribus. On the other hand, as pointed out above, the (initially) lower difference between $F V_{0}$ and $F V_{0}^{\alpha}$ has an adverse effect. However, as is evident from Figure 1 , negative (and positive) differences between $F V_{t}$ and $F V_{0}^{\alpha}$ are rather to be expected in the long run, and such later deficit (or excess) benefits for the MIA product tend to be stronger the longer the time horizon is. Even though negative differences are weighed less now, the enormous upside potential for strongly positive realizations of $A D V_{\mathrm{MIA}}^{\alpha}$ is compressed by stronger discounting, and as lower levels of e.g. $\mathbb{E}\left[A D V_{\text {MIA }}^{\alpha}\right]$ in Table 4 compared to the base case show, the latter effect obviously prevails.

A stronger discounting in the case of $i=5 \%$ also causes such negative differences of benefits to have a lower impact on the advantageousness of MIA. i.e. deficits (and excesses, likewise) are far more attenuated as already mentioned, and the obvious consequence for treatment $A_{I I}$ in comparison to the base case can also be observed from Table 4 versus Table 3 ; the empirical variances are less than two thirds of what they had been before. Interestingly, the expected shortfalls are less dispersed for different levels of $\alpha$ (in absolute terms). Yet they are higher or lower now compared to treatment $A_{I}$ which is somewhat contradictory in the view of the higher means and reduced variances. Obviously, there is an effect that causes the tails to be fatter now.

\section{Treatments $B_{I}$ and $B_{I I}$}

If the much smaller portfolios from treatments $B_{I}$ and $B_{I I}$ with only $l_{60}=1,000$ insureds are considered, the above findings still apply accordingly. More precisely, the higher interest rate of $5 \%$ in treatment $B_{I I}$ versus a moderate $3 \%$ in treatment $B_{I}$ has an overall effect that is similar to the above comparison of $A_{I}$ and $A_{I I}$. The initial annuity benefits $F V_{0}$ and $F V_{0}^{\alpha}$ are higher for the higher interest rate and the empirical means are significantly lower under higher interest rates. This is again the immediate consequence of a compression of the distributions of $A D V_{\text {MIA }}^{\alpha}$, but of course contingent on $\alpha$. The difference can also be identified in the diagrams in Figure 5 versus those in Figure 4, and Tables 5 and 6 give the relevant key figures. Similar to the previous cases of treatments $A_{I}$ and $A_{I I}$, the distributions under a higher interest rate are more compressed, which is evident from a reduction of the variances by roughly one third and likewise less negative expected shortfalls (or "expected policyholder disadvantageousness" of MIA). However in the "B" case no effect on the tails of the distribution of $A D V_{\text {MIA }}^{\alpha}$ can be identified. Thus, a higher interest rate works in a similar same fashion here despite the lower number of contracts in the underlying portfolios of insured. One conclusion is that results are much more sensitive to discounting than they are to different portfolio sizes.

However, another observation is the overall difference of the results under treatments $B_{I}$ and $B_{I I}$ compared to those in the case of larger annuity portfolios. Obviously, the fact that the Law of Large Numbers works less well here causes stronger deviations of the actual number of survivors from the initial best estimates. Accumulating over time, these deviations cause 
Figure 4: Empirical Distribution of $A D V_{\text {MIA }}^{\alpha}$ - Treatment $B_{I}$
(a) $\alpha=0.001$
(b) $\alpha=0.005$
(c) $\alpha=0.010$
$F V_{0}^{\alpha}=5,285.50$
$F V_{0}^{\alpha}=5,334.00$
$F V_{0}^{\alpha}=5,358.50$
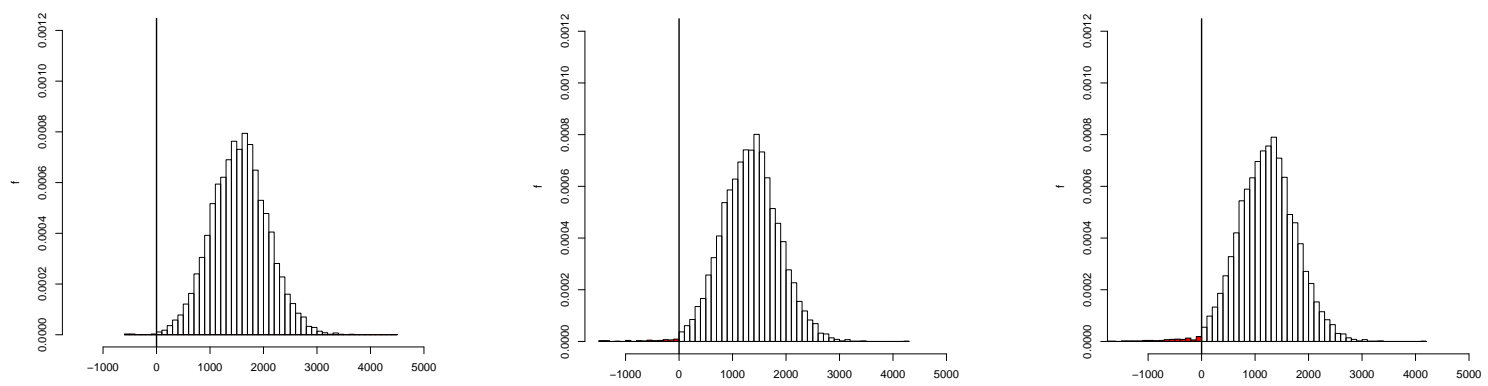

Source: authors' calculation, based on data provided by the CMI.

Table 5: Key Figures from Treatment $B_{I}$

\begin{tabular}{|l||r|r|r|}
\hline Annuity Benefits & $\alpha=0.001$ & $\alpha=0.005$ & $\alpha=0.010$ \\
\hline \hline$F V_{0}$ & $5,285.50$ & $5,334.00$ & $5,358.50$ \\
\hline$F V_{0}^{\alpha}$ & \multicolumn{3}{|c|}{$5,631.67$} \\
\hline \hline Risk Measure & $1,552.15$ & $1,335.36$ & $1,224.22$ \\
\hline $\mathbb{E}\left[A D V_{\text {MIA }}^{\alpha}\right]$ & 0.001 & 0.005 & 0.010 \\
\hline $\mathbb{P}\left[A D V_{\text {MIA }}^{\alpha}<0\right]$ & $274,235.1$ & $285,507.6$ & $297,112.2$ \\
\hline $\operatorname{Var}\left[A D V_{\text {MIA }}^{\alpha}\right]$ & -329.35 & -501.95 & -577.94 \\
\hline $\mathbb{E}\left[A D V_{\text {MIA }}^{\alpha} \mid A D V_{\text {MIA }}^{\alpha}<0\right]$ & -34 . \\
\hline \multicolumn{4}{|c||}{ Source: authors' calculation, based on data provided by the CMI. }
\end{tabular}

a more dispersed distribution of per-policy reserves for the conventional product used as a benchmark. In turn, to reduce deficit reserves here and make the benchmark comparable, the contingency funds need to be increased compared to the case of the larger portfolios discussed before. In turn, conventional annuities deliver benefits that are smaller in the "B" treatments when compared to the respective numbers from the "A" treatments. This is evident from the values for $F V_{0}^{\alpha}$ in Tables 5 and 6, respectively. Thus, in (3.11) the differences between $F V_{t}$ and $F V_{0}^{\alpha}$ tend to be larger ceteris paribus, and this immediately leads to values of $A D V_{\text {MIA }}^{\alpha}$ that are generally higher. In short: the "B" distributions are shifted to the right, which is also evident e.g. from the higher empirical means in Tables 5 and 6 when compared to Tables 3 and 4, respectively. Interestingly, the dispersions in treatments with smaller portfolios are roughly $1.24-1.27$ times what they had been before, and as a direct consequence expected "shortfalls" take on more negative values due to a less perfect diversification. In general, the overall prospect for benefits under MIA is considerably better for smaller portfolios. However, if negative developments occur they are slightly more severe than in the case of larger annuity portfolios with the exception of $A_{I I}$, possibly due to some effect on the tails. 
Figure 5: Empirical Distribution of $A D V_{\mathrm{MIA}}^{\alpha}$ - Treatment $B_{I I}$
(a) $\alpha=0.001$
(b) $\alpha=0.005$
$F V_{0}^{\alpha}=6,681.65$
(c) $\alpha=0.010$
$F V_{0}^{\alpha}=6,630.00$
$F V_{0}^{\alpha}=6,706.70$
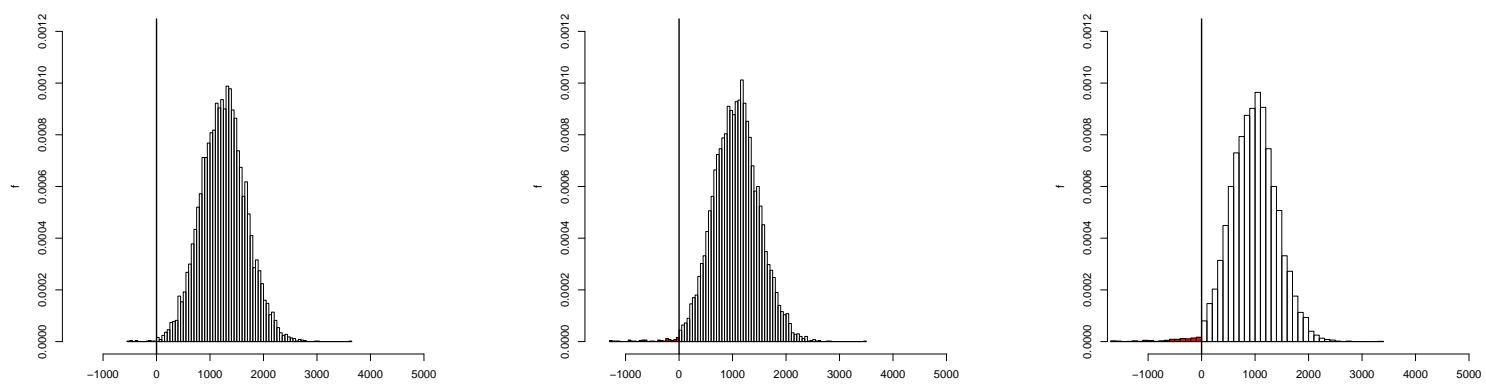

Source: authors' calculation, based on data provided by the CMI.

Table 6: Key Figures from Treatment $B_{I I}$

\begin{tabular}{|c|c|c|c|}
\hline Annuity Benefits & $\alpha=0.001$ & $\alpha=0.005$ & $\alpha=0.010$ \\
\hline$\overline{F F V_{0}}$ & \multicolumn{3}{|c|}{$6,975.56$} \\
\hline$F V_{0}^{\alpha}$ & $6,630.0$ & $6,681.65$ & $6,706.70$ \\
\hline \multicolumn{4}{|l|}{$\overline{\text { Risk Measure }}$} \\
\hline $\mathbb{E}\left[A D V_{\mathrm{MIA}}^{\alpha}\right]$ & $1,252.78$ & $1,066.36$ & 974.60 \\
\hline $\mathbb{P}\left[A D V_{\mathrm{MIA}}^{\alpha}<0\right]$ & 0.001 & 0.005 & 0.010 \\
\hline $\operatorname{Var}\left[A D V_{\mathrm{MIA}}^{\alpha}\right]$ & $179,131.4$ & $186,334.4$ & $193,778.4$ \\
\hline $\mathbb{E}\left[A D V_{\text {MIA }}^{\alpha} \mid A D V_{\text {MIA }}^{\alpha}<0\right]$ & -273.36 & -433.16 & -488.91 \\
\hline
\end{tabular}




\section{Summary and Conclusion}

As discussed in Section 1, the rather welcome longevity trend also has some implications that have to be cautiously accounted for by both individuals and insurance companies. For the latter, when doing annuity and pension business, there is evidence that the aggregate form of longevity risk transferred by such contracts represents a severe systematic risk. It is obvious that the high correlation of individual risks and thus the potential for accumulative losses are a major drawback for insurers. More precisely, unforeseen deviations of actual mortality development from previous expectations can barely - if at all - be hedged or diversified so that the question seems legitimate if insurers should decline to assume this particular risk.

Following the example of German private health insurance that was briefly introduced in Section 2.3 as a "role model", a redesign of conventional life annuities is proposed where benefits contingent on survival are linked to actual mortality experience of a certain reference group. The fact that such products basically do not seem to exist appears rather astonishing given the existence of similar product innovations, such as e.g. unit-linked products. The mortality-indexed annuities (MIA) are further analyzed by comparing their variable benefits to those from a comparable conventional product, assuming that the latter would include a safety margin or contingency funds to reduce the insurer's risk of incurring deficit reserves as discussed in further detail in Section 3.3 . The benchmark product also includes a sizeable (mortality) surplus participation through a terminal bonus. Effectively, the annual differences of benefits from MIA and comparable contracts are aggregated similar to an actuarial present value of these differences using actual survival rates.

The results from a Monte-Carlo simulation under various parameterizations presented in Section 4.2 reveal that policyholders are in general better off with the innovative MIA, although there is some risk. More precisely, the degree of advantageousness varies greatly, i.e. empirical distributions feature relatively large dispersions, and this is a direct consequence of the fact that aggregate longevity risk is effectively not transfered but borne by the insured. The overall tendency, though, is a pronounced advantageousness of MIA since contingency funds are not necessary here so that MIA benefits are generally higher. The downside risk in the sense that MIA may actually be disadvantageous for policyholders, i.e. benefits from MIA become lower than in a comparable conventional annuity contract, is just as low as the remaining deficit risk for the benchmark annuity provider.

Results obviously depend on this quantity and thus the safety loading of the benchmark product. The smaller it is the larger the loading or equivalently the difference in (initial) benefits. As a higher difference provides an additional head start for mortality-indexed annuities, it is logically consistent that the degree of advantageousness as measured by $A D V_{\text {MIA }}^{\alpha}$ increases as $\alpha$ and thus the adverse potential for policyholders decreases. The upside potential can be a strong argument in favor of MIA, as similar to the transition from conventional annuities to investment-linked contracts, some policyholders may find it appealing to be offered such contracts. Yet, further analyses would also have to take into account the individual attitude towards risk or, more precisely, the degree of risk aversion.

What needs to be further considered is the fixed guaranteed interest rate for both the MIA and the conventional annuity, assumed to be either $3 \%$ or $5 \%$. In reality, it is not unlikely that the insurer's investments of the collected premiums (or policy reserves) will yield higher returns. 
One may thus argue that it is not adequate to assume such a simple annuity contract without (investment) profit sharing. For instance, German insurance companies have traditionally almost exclusively offered participating insurance contracts in both the life insurance and the annuities markets 51

However, that approach leads to an entirely different regime of guarantee(s) ${ }_{52}^{52}$ and it highly depends on the regulatory or legislative environment. Besides a potential increase of risk exposure for insurance companies contingent on the design of policy guarantees, ${ }^{53}$ it also raises the question of how such mechanisms or guarantees would have to be valued 54 Nevertheless, a further analysis aiming at a higher degree of reality could assume stochastic investment yields from a suitable mix of e.g. stocks and bonds, combined with a mechanism of profit sharing. Yet, the computational complexity of the model presented here would be greatly increased. In tendency, both the innovative MIA as well as the benchmarking annuities would be even more profitable for policyholders, and it remains to be seen whether the overall effect would change the results discussed above.

Another important caveat must be made at this point as the problems arising from model uncertainty are ignored in the present investigation. Rather it was assumed that the LC/PML approach represents the model underlying actual mortality so that the insurer's projections based on the same model were only subject to the explicit stochasticity incorporated in the LC/PML model. Also, parameter uncertainty might render the model calibration and thus projections erroneous. Reality is likely to originate more sophisticated fluctuations or structural changes, and it remains a challenge for the industry and academia to improve and further the achievements of adequate mortality modeling.

Both uncertainties will actually increase the variations of ultimate reserves for the benchmark product, so that the safety loading would have to be larger to still attain the same low shortfall risk. This would in turn lead to higher levels of advantageousness, but the MIA benefits would also be more dispersed so that the overall effect remains ambiguous at this point. The same argument applies when considering alternative mortality models that might be less conservative and produce more deviating projections.55

Insofar as the models used for projections by the insurance company (or prescribed by regu-

${ }^{51}$ For an insightful analysis of annuity types and different designs offered in the German market as well as an evaluation for different types of customers, see von Gaudecker and Weber (2004).

52 The rather complex mechanism of accounting provisions regarding surplus determination shifts the attributable profits across periods, and ultimately allocated it to individual contracts. In addition, despite the existence of certain provisions insurance companies enjoy a wide flexibility in the shifting of profits across time. The German Federal Court of Justice recently criticized the prevailing practice of insurers' surplus attribution, which largely favored uncanceled contracts by means of overly large terminal bonuses, for its lack of transparency; see BGH IV ZR 162/03, IV ZR 177/03, IV ZR 245/03. Providers were thus obliged to "adequately" account for the development of reserves underlying surplus participation. As a consequence $\S 153$ VVG (Versicherungsvertragsgesetz) was revised and the Verordnung über die Mindestbeitragsrückerstattung in der Lebensversicherung (Mindestzuführungsverordnung - MindZV) as of April 04, 2008 (see BGBl. I S. 690) replaced the previously applicable Verordnung über die Mindestbeitragsrückerstattung in der Lebensversicherung (ZRQuotenV) as of July 23, 1996 (see BGBl. I S. 1190) for new business.

${ }^{53}$ See Kling et al. (2007) for an analysis in the case of life insurance companies. They note the dominant role of the design of the guarantee as this largely influences their findings.

54 See Bauer et al. (2006).

55 A relatively simple way to mimic increasing uncertainty about projections over time could consist in multiplying the ARIMA disturbance term used to model the time index in the LC/PML approach with a factor increasing over time, such as e.g. $\left(1+\frac{t}{100}\right)$. 
lators) are considered faulty or insufficient, model uncertainty or diagnosis risk ${ }^{56}$ gives insurers an incentive to include additional safety margins to account for these risks, and this would further improve the advantageousness of the proposed MIA.

It is also to be noted that under the present setup the MIA product effectively transfers not only systematic mortality (or longevity) risk back to policyholders but also the unsystematic portion. When adjusting benefits, fluctuations of the number of survivors are not further distinguished with respect to their origin, i.e. to what extent they arise from general changes in the underlying mortality pattern (systematic risk) or whether they are due to the deviation of individuals' mortality from the portfolio average 57 This observation directly connects to the issue of which portfolio's mortality experience may be used by the insurer to make adjustments.

The chosen implementation assumes that the actual portfolio mortality experience may serve as the relevant measure for adjustments of benefits. Effectively, more risk than initially discussed is shifted back to policyholders, and it may be worthwhile to reflect on the question whether such a strong(er) cutback of risk otherwise borne by the annuity provider is conducive. Recall that the objective of the proposed MIA was to reduce or avoid the potential for accumulative losses due to systematic changes in the longevity trend. When also shifting back the unsystematic portion of longevity risk, this objective is obviously exceeded. Of course, an alternative would be to model an additional mortality experience that not necessarily coincides with that of the portfolio under investigation. An example of such "more general" data would be an industry or population index, or an aggregate company measure that also includes other lines of life or annuity business. However, the reason for not incorporating such diverging mortality experiences here is a facilitation of the computations.

Eventually the fact that the present case can be considered the most extreme scenario of risk avoidance can be taken as an argument to consider the present results as the "worst case" for policyholders ${ }^{58}$ When only shifting back the systematic risk, some thoughts on the tendency of changes in results are possible. Naturally, the insurer still bears the unsystematic longevity risk, the result would in tendency be better for the policyholders, as the difference of adjusted benefits compared to a comparable conventional product would be larger ceteris paribus. Following the argumentation in Section 3.3. contingency funds could now also be necessary for the MIA contracts due to the unsystematic risk borne by the insurer. As this might counteract the improvement of $A D V_{\mathrm{MIA}}^{\alpha}$ sketched before, the overall effect is ambiguous and thus further analyses are indispensable.

Another extension of the present paper could be costs and expenses. As pointed out earlier, the present assessment was entirely made on a net actuarial basis, i.e. without costs, expenses, or (investment) profit-sharing etc. - with the exception of the safety loading for the benchmark

56 Karten (2000) identifies diagnosis risk as the uncertainty about an insurer's assumption regarding the stochasticity of losses. This term thus almost coincides with that of model uncertainty.

57 Of course, the latter cause would be the effect of an imperfect diversification across individual risks in the portfolio of contracts. More formally, the effect asserted by the Law of Large Numbers only holds for a theoretically infinite number of contracts, and as this never coincides with reality there is the risk of such deviations.

${ }^{58}$ An interesting argument to consider is that fact that the entire mortality risk is effectively borne by the policyholders, which is as a distinct feature of a mutual insurer. In that case, however, no self-contained insurance company would be in charge of bearing a certain portion of the risk transfered by policyholders, but instead the party referred to as the annuity provider consists in an entity organizing the balancing of risks among the members of this mutual insurer, but does not bear any risk itself. 
product. Actual products rarely offer a fair premium without any surcharges or loadings, and costs that are typically included pertain to the policy acquisition (i.e. commissions payable to insurance agents and the costs of checking and processing applications) and the running of the insurance company 59 For a true comparison, not only MIA but also the benchmark product would have to include expenses and loadings, and it is not obvious at this point in which case the respective costs would be higher.

Further discussion and deliberations regarding mortality-indexed annuities (MIA), which upon closer investigation do not appear so surprising, may be necessary to ultimately appraise whether the indicated advantages outweigh potential problems associated with this concept. In the view of the potentially advantageous features of mortality-linked annuities, individuals who in general seem to be rather reluctant to buy life annuitie ${ }^{60}$ could be given additional incentives to do so.

\footnotetext{
${ }^{59}$ Many actuarial textbooks provide an introduction of how to include initial and recurring costs into pricing and reserving of insurance contracts as a transition from a net perspective presented in the first place; see e.g. Bowers et al. (1997, Ch.15).

60 This empirical observation in contrast to the theoretical optimality of complete annuitization of wealth is generally discussed in the literature as the "annuity puzzle"; see Yaari (1965); Davidoff et al. (2005).
} 


\section{References}

Akerlof, George A. (1970). "The Market for Lemons - Quality Uncertainty and the Market Mechanism." Quarterly Journal of Economics, 84(3): 488-500.

Alho, Juha M. (2000). "Discussion of Lee (2000)." North American Actuarial Journal, 4: 91-93.

Bauer, Daniel, Rüdiger Kiesel, Alexander Kling, and Jochen Russ (2006). "Risk-Neutral Valuation of Participating Life Insurance Contracts." Insurance: Mathematics and Economics, 39(2): 171-183.

Black, Kenneth and Harold D. Skipper (2000). Life and Health Insurance. Upper Saddle River, NJ: Prentice Hall, 13th edn.

Blake, David, Andrew J. CaIrns, and Kevin Dowd (2003). "Annuitisation Options." Prepared for the Global Issues in Insurance Regulation conference.

Bowers, Newton L., Hans U. Gerber, James C. Hickman, Donald A. Jones, and Cecil J. Nesbitt (1997). Actuarial Mathematics. Schaumburg, Illinois: Society of Actuaries, 2nd edn.

Brouhns, Natacha, Michel Denuit, and Jeroen K. Vermunt (2002). "A Poisson log-bilinear regression approach to the construction of projected lifetables." Insurance: Mathematics and Economics, 31: 373-393.

BRÜNJES, Christian (1990). Technische Methoden der privaten Krankenversicherung in Deutschland, 44-62. In: Timmer (1990).

Cairns, Andrew J., David Blake, and Kevin Dowd (2006). "Pricing Death: Frameworks for the Valuation and Securitization of Mortality Risk." ASTIN Bulletin, 36: 79-120.

Davidoff, Thomas, Jeffrey R. Brown, and Peter A. Diamond (2005). "Annuities and Individual Welfare." The American Economic Review, 95: 1573-1590.

De Moivre, Abraham (1756). The Doctrine of Chances: Or, a Method of Calculating the Probability of Events in Play. London: A. Millar, 3rd edn. Reprinted in 1967 by Chelsea, New York.

EBers, Markus (2001). Die Überschußbeteiligung in der Lebensversicherung. Baden-Baden: Nomos.

Edwards, Ryan D., Ronald D. Lee, Michael W. Anderson, Shripad Tuljapurkar, and Carl Boe (2003). "Key Equations in the Tuljapurkar-Lee Model of the Social Security System." Michigan Retirement Research Center, Working Paper 2003-044.

Feldstein, Martin S. (1970). "The Rising Price of Physicians' Services." Review of Economics and Statistics, 52: 121-133.

Feldstein, Martin S. (1971). "Hospital Costs Inflation: A Study in Nonprofit Price Dynamics." American Economic Review, 61: 853-872. 
Feldstein, Martin S. (1973). "The Welfare Loss of Excess Health Insurance." Journal of Political Economy, 81: 251-280.

von Gaudecker, Hans-Martin and Carsten Weber (2004). "Surprises in a Growing Market Niche: An Evaluation of the German Private Life Annuities Market." The Geneva Papers on Risk and Insurance, Issues and Practice, 29: 394-416.

GDV (2004). "Die Märkte für Altersvorsorge in Deutschland: Eine Analyse bis 2020." No. 23 in Schriftenreihe des Ausschusses Volkswirtschaft. Karlsruhe: Verlag Versicherungswirtschaft.

GDV (2008). "Statistical Yearbook of German Insurance." Berlin: Gesamtverband der Deutschen Versicherungswirtschaft e.V. URL https://secure.gdv.de/gdv-veroeffentlichungen/upload_img/146_dwl.pdf.

GOMPERTz, Benjamin (1825). "On the nature of the function expressive of the law of human mortality." Philosophical Transactions, 27(5): 513-519.

Gruschinske, G. (1989). "Überschußbeteiligung in der Lebensversicherung in der Diskussion." Zeitschrift für Versicherungswesen, 40: 642-648.

Hanewald, Katja, Thomas Post, and Helmut Gründl (2009). "Stochastic Mortality, Macroeconomic Risks, and Life Insurer Solvency." Humboldt-Universität Berlin, Working Paper.

KARTen, Walter (1989a). "Versicherungstechnisches Risiko - Begriff, Meassung und Komponenten (I)." WISU-Das Wirtschaftsstudium, 18: 105-108.

Karten, Walter (1989b). "Versicherungstechnisches Risiko - Begriff, Meassung und Komponenten (II).” WISU-Das Wirtschaftsstudium, 18: 169-174.

Karten, Walter (2000). "Versicherungstechnisches Risiko - Begriff, Meassung und Komponenten." In: Hesberg, Dieter, Martin Nell, Andreas Richter, and Winfried Sснотт (Eds.), "Versicherungsbetriebslehre - Kernfragen aus entscheidungsorientierter Sicht," chap. 3, 49-69. Karlsruhe: Verlag Versicherungswirtschaft. Reprinted from Karten (1989ab).

Kifmann, Mathias (2000). "The Premium Risk Problem in Health Insurance." Schmollers Jahrbuch - Zeitschrift für Wirtschafts- und Sozialwissenschaften, 120: 567-586.

Kifmann, Mathias (2002). Insuring Premium Risk in Competitive Health Insurance Markets, vol. 15 of Beiträge zur Finanzwissenschaft. Tübingen: Mohr Siebeck. ISBN 9783161477409.

KLing, Alexander, Andreas Richter, and Jochen Russ (2007). "The Impact of Surplus Distribution on the Risk Exposure of With Profit Life Insurance Policies Including Interest Rate Guarantees." Journal of Risk and Insurance, 74(3): 571-589. doi:10.1111/j.1539-6975.2007.00225.x.

LEe, Hangsuck (2003). "Pricing equity-indexed annuities with path-dependent options." Insurance: Mathematics and Economics, 33(3): 677-690. ISSN 0167-6687. doi:10.1016/j.insmatheco.2003.09.006. 
LeE, Ronald D. (2000). "The Lee-Carter Method For Forecasting Mortality, with Various Extensions and Applications." North American Actuarial Journal, 4: 80-91.

Lee, Ronald D., Michael W. Anderson, and Shripad Tuljapurkar (2003). "Stochastic Forecasts of the Social Security Trust Fund." Report prepared for the Social Security Administration. Michigan Retirement Research Center, Working Paper 2003-043.

LEE, Ronald D. and Lawrence R. CARTER (1992). "Modeling and forecasting US mortality." Journal of the American Statistical Association, 87: 659-675.

Lee, Ronald D. and Shripad Tuluapurkar (1998). Stochastic Forecasts for Social Security, chap. 9, 393-430. Chicago: University of Chicago Press.

Leinert, Johannes and Gert G. WaGner (2001). "Probleme einer steigenden Lebenserwartung in der privaten Rentenversicherung: Theorie und Empirie für Deutschland." DIW Discussion Paper No. 258.

Lin, X. Sheldon and Ken Seng TAN (2003). "Valuation of Equity-Indexed Annuities under Stochastic Interest Rates." North American Actuarial Journal, 7(4): 72-91.

Makeham, William M. (1860). "On the law of mortality and the construction of annuity tables." Journal of the Institute of Actuaries, 8: 301-310.

Montgomery, Keith (2007). "The Demographic Transition." Working Paper, University of Wisconsin-Marathon County. Retrieved October 28, 2007 from http://www.uwmc.uwc.edu/geography/Demotrans/demtran.htm

MutschleR, Karin and Jochen Russ (2001). "Die Fondsgebundene Rentenversicherung mit Fondsanbindung in der Rentenbezugsphase - Produktideen und empirische Analysen." Blätter der Deutschen Gesellschaft für Versicherungs- und Finanzmathematik, 25(1): 95-110. doi:10.1007/BF02857120.

Nell, Martin, Andreas Richter, and Jörg Schiller (2009). "When prices hardly matter: Incomplete insurance contracts and markets for repair goods." European Economic Review, (in press).

Oeppen, Jim and James W. Vaupel (2002). "Broken Limits to Life Expectancy." Science, 296: $1029-1031$.

PAVCNIK, Nina (2002). "Do pharmaceutical prices respond to patient out-of-pocket expenses?" RAND Journal of Economics, 33: 469-487.

Renshaw, Arthur E. and Steven Haberman (2003). "Lee-Carter mortality forecasting with age-specific enhancement." Insurance: Mathematics and Economics, 33(2): 255-272.

Riemer-Hommel, Petra and Thomas Trauth (2005). "The Challenge of Managing Longevity Risk." In: Frenkel, Michael, Ulrich Hommel, and Markus Rudolf (Eds.), "Risk Management - Challenge and Opportunity," 391-406. Berlin: Springer, 2nd edn.

Russ, Jochen (2000). "Todesfall-Leistung bei der Fondsgebundenen Rente - Betrug oder Performancesteigerung?" Online at http://www.ifa-ulm.de/downloads/Performance_im_Todesfall.pdf 
Schumacher, Petra (2008). "Enhanced Annuities - Produktinnovation als

Lösungsstrategie für das Annuity Puzzle?" Zeitschrift für die gesamte

Versicherungswissenschaft, Suppl. 2008: 71-89. doi:10.1007/s12297-008-0036-4.

Schwintowski, Hans-Peter and Martin Ebers (2002). "Lebensversicherung - stille Reserven - Überschussbeteiligung." Zeitschrift für die gesamte Versicherungswissenschaft, 91(3): 393-452.

Timmer, Hans-Georg (1990). Technische Methoden der privaten Krankenversicherung in Europa - Marktverhältnisse und Wesensmerkmale der Versicherungstechnik. No. 23 in Schriftenreihe Angewandte Versicherungsmathematik. Karlsruhe: Verlag Versicherungswirtschaft.

Tiong, Serena (2000). "Valuing Equity-Indexed Annuities." North American Actuarial Journal, 4(4): 149-170.

United Nations (2005). "World Population Prospects. The 2004 Revision - Highlights." Report.

YAARI, Menahem E. (1965). "Uncertain Lifetime, Life Insurance, and the Theory of the Consumer." Review of Economic Studies, 32: 137-150.

Zweifel, Peter and Luca Crivelli (1996). "Price Regulation of Drugs: Lessons from Germany." Journal of Regulatory Economics, 10: 257-273. 